\title{
BANK COMPETITION AND ECONOMIC STABILITY: THE ROLE OF MONETARY POLICY ${ }^{\dagger}$
}

\author{
SYLVAIN CHAMPONNOIS*
}

February 15, 2009

\begin{abstract}
This paper analyzes the dual role of monetary policy for economic efficiency and stability in a model of endogenous bank competition. Multiple equilibria emerge from the complementarity between bank and non-financial firm decisions. Adverse aggregate or idiosyncratic liquidity shocks may cause a breakdown in which the economy collapses into a no-production equilibrium. Less bank competition improves the profitability of banks and makes the economy less vulnerable to adverse shocks but it also distorts the efficient allocation of capital. This stability/efficiency tradeoff creates a motive for monetary policy to be tight when liquidity is abundant to spur bank competition and to be loose in bad times to restore the profitability of banks and decrease the likelihood of economic and financial crashes.
\end{abstract}

KEYwORDS. Banking sector, competition, monetary policy, aggregate and idiosyncratic liquidity shocks, systemic risk, sticky entry, stress-testing.

\footnotetext{
* Rady School of Management, University of California, San Diego. Email: sylvain@ucsd.edu.

$\dagger$ I am grateful to Patrick Bolton and Jonathan Parker for their guidance and to Dominique Lauga, Romain Rancière, Jose Scheinkman, Hyun Shin and seminar participants at UCSD and the Paris School of Economics for helpful comments. A previous version of this paper has circulated as "Bank competition and development." Any errors are mine alone.
} 
Recent events have shown that adverse liquidity shocks can pose a risk not just to individual institutions, but also to the stability of the banking sector. During financial crises, bank financial stress and conservative lending policies contribute to a weaker economic environment which in turn exacerbates financial stress. These adverse feedback loops between the real economy and the financial sector have become a central concern for monetary authorities. In 2008 for instance, Ben Bernanke, Chairman of the US Federal Reserve, has repeatedly described these vicious dynamics and their dangerous impact on the economy. ${ }^{1}$ In a speech to the Greater Austin Chamber of Commerce on December 1, 2008, Bernanke argues that easing aggressively monetary policy has reduced the systemic risk associated to adverse feedback loops "in which economic weakness exacerbates financial stress, which, in turn, leads to further economic damage." What tradeoffs do central banks face when they ease monetary policy to fight financial crises?

This paper formalizes an efficiency/stability tradeoff for monetary policy in a general equilibrium model of bank competition. On the liability side, bank managers raise deposits from risk-averse investors who can also invest in riskfree securities. On the asset side, bank managers compete to lend to entrepreneurs whose investment choices depend on the decisions of the other agents, which creates a coordination problem. We show that in general two stable equilibria exist: a production equilibrium with many firms and banks and a no-production equilibrium. A monetary authority maximizing welfare trades efficiency for stability. ${ }^{2}$ In the production equilibrium, a tight monetary policy through high riskfree interest rates forces entrepreneurs to set risky interest rates efficiently close to the maximum technological rate.

\footnotetext{
${ }^{1}$ In contrast, the concern with bank runs is remote. In his 24 speeches in 2008, Bernanke only refers to bank runs to describe the collapse of Bear Stearns triggered by "a run of its creditors and customers, analogous to the run of depositors on a commercial bank" (Annual Economic Symposium, Jackson Hole, Wyoming, August 22, 2008). See Section I for a relation to the bank run literature.

${ }^{2}$ Welfare in this model is defined as the expected utility of investors. The utility of risk-neutral entrepreneurs and bank managers only depends on their profits which are zero because of free entry.
} 
Small shocks in production or expected productivity lead to small adjustments in the number of firms and banks, and in the portfolio composition. But under large liquidity shocks, the production equilibrium might disappear, leading to an economic collapse and the exit of firms and banks. A looser monetary policy facilitates the flow of funds to credit markets and allows firms and banks to return to profitability.

The main argument of this paper is that monetary policy plays a dual role in controlling the efficiency and stability of the allocation of capital. A tighter monetary policy fosters competition and decreases distortionary markups but it also decreases the local stability of the production equilibrium, making it less resilient to liquidity shocks. Systemic risk and contagion emerge when there are short-term constraints on bank entry. ${ }^{3}$ Idiosyncratic shocks that lead to the failure of several banks can cause an increase in the markups charged for financial services which decreases the investment and firm profits and causes some firms to exit; the bank profits drop which forces the failure of more banks. The speed with which these vicious dynamics can be unleashed in modern financial systems can lead to complete economic and financial breakdowns. ${ }^{4}$

This paper provides microfoundations to a monetary reaction function that depends on aggregate and idiosyncratic liquidity shocks. The framework links the ex-ante assessment of macroeconomic and microeconomic risks to the ability of the financial sector to overcome shocks. These assessments are performed routinely by central banks using stress testing methods in order to conduct of monetary policy (see Bank of England, 2008; European Central Bank, 2008; International Monetary Fund, 2008). The rents of firms and banks serve as a buffer against shocks but also embody the distortions in the allocation of capital.

\footnotetext{
${ }^{3}$ De Bandt and Hartmann (2002) review the concepts and literature on systemic risk.

${ }^{4}$ Short-term bank entry constraints can lead to crashes and convergence to the no-production equilibrium even though the production equilibrium exits. Other interpretations of crashes in multiple equilibria environments include adverse market sentiment in which bad expectations can become self-fulfilling.
} 
Interest rate policy controls the size of these rents by trading stability and efficiency. The correlation between bank competition (or bank concentration) and economic growth, which is explained here by the efficiency of the capital allocation, is consistent with empirical evidence suggesting that bank competition fosters industrial growth (Jayaratne and Strahan, 1996; Claessens and Laeven, 2005). ${ }^{5}$ The fact that the number of firms increases (decreases) more rapidly than the number of banks in an economic boom (recession) predicts that bank firm leverage is procyclical, consistent with Adrian and Shin (2008, forthcoming).

The model has two main ingredients. First, the payoffs of projects are imperfectly correlated, with each project marginally increasing the risk-diversification of risk-averse investors. Entrepreneurs are aware of the risk-diversification they provide by issuing securities and they exercise some market power when raising external finance. Second, the transfer of funds from a risk-averse investor to the entrepreneurs depends on a population of specialized financial intermediaries ("banks") that compete in the price of financial services. The complementarity between production and financing can be interpreted either as geographical complementarity due to the role of distance (Petersen and Rajan, 1995; Degryse and Ongena, 2005) or as informational complementarity (soft versus hard information, see Berger, Miller, Petersen, Rajan, and Stein, 2005). The competition between banks modeled as spatial competition is related to Sussman (1993); Besanko and Thakor (1992). ${ }^{6}$ This allows bank managers to appropriate to some rents. Free entry drives the profits of entrepreneurs and bank managers

\footnotetext{
${ }^{5}$ Claessens and Laeven (2004); Claessens, Demirguc-Kunt, and Huizinga (2003) describe the degree of bank competition and the penetration of foreign banks across countries. However, theoretical predictions are ambiguous (see Rajan, 1992; Petersen and Rajan, 1995 and the discussions in Claessens and Laeven, 2005; Cetorelli and Strahan, 2006).

${ }^{6}$ In Diamond (1984); Williamson (1986), banks emerge because they have a cost and a diversification advantage. If the payoffs of firms are imperfectly correlated, each intermediary has to lend to all the firms. Here banks only lend to a fraction of borrowers. Moreover, in contrast to Dick (2008), banks differ in only one dimension and only one bank lends to one type of firm.
} 
to zero and pins down the endogenous competition among banks, the size of the industrial sector and the risk-diversification of the representative investor. The model is tractable and in particular it allows the aggregation of the decisions of heterogeneous firms in closed form.

The paper is organized as follows. Section I reviews the related literature. Section II outlines the static model. Section III characterizes the equilibria and analyzes their properties and the implications for monetary policy. Section IV introduces a model in which investment and financing decisions are taken jointly by a conglomerate and further analyzes the tradeoff between stability and efficiency. Section V concludes. Proofs are contained in the appendix.

\section{Related LiteratuRE}

I.1. Financial fragility. The fragility of banks on the liability side has been emphasized by a large theoretical literature starting from Diamond and Dybvig (1983). In contrast, this paper focuses on the fragility of banks on the asset side. The lending opportunities of a bank are endogenous and depend on the number of firms and the competition between banks. The bank liabilities are the deposits of investors and are set without frictions. ${ }^{7}$ In contrast to Diamond and Dybvig (1983) (and more recently Repullo, 2005; Rochet and Vives, 2004) who consider models with a representative bank, we emphasize here the systemic importance of free entry conditions for a population of banks and non-financial firms.

I.2. Complementarities in investment and financing. Brunnermeier and Pedersen (2007) show that financing frictions through margin requirements create complementarities between funding and investment, leading to destabilizing dynamics. Saint-Paul (1992) shows that multiple equilibria can exist due to a coordination failure between technology and financing decisions. In Saint-Paul's model, the technology and financing decisions are strategic complements because the higher risks of the high-yield technology are offset by

\footnotetext{
${ }^{7}$ The setup differs from Winton (1997); Yannelle (1997): there is no coordination problem among lenders and banks are not identical as they specialize in lending to certain projects.
} 


\section{FiguRE 1.}

Balance-sheet multiplier. The figure shows how initial bank losses can propagate. The tight credit conditions represent the higher financing markups charged by banks. The tighter investment conditions represent the higher investment markups charged by non-financial firms.

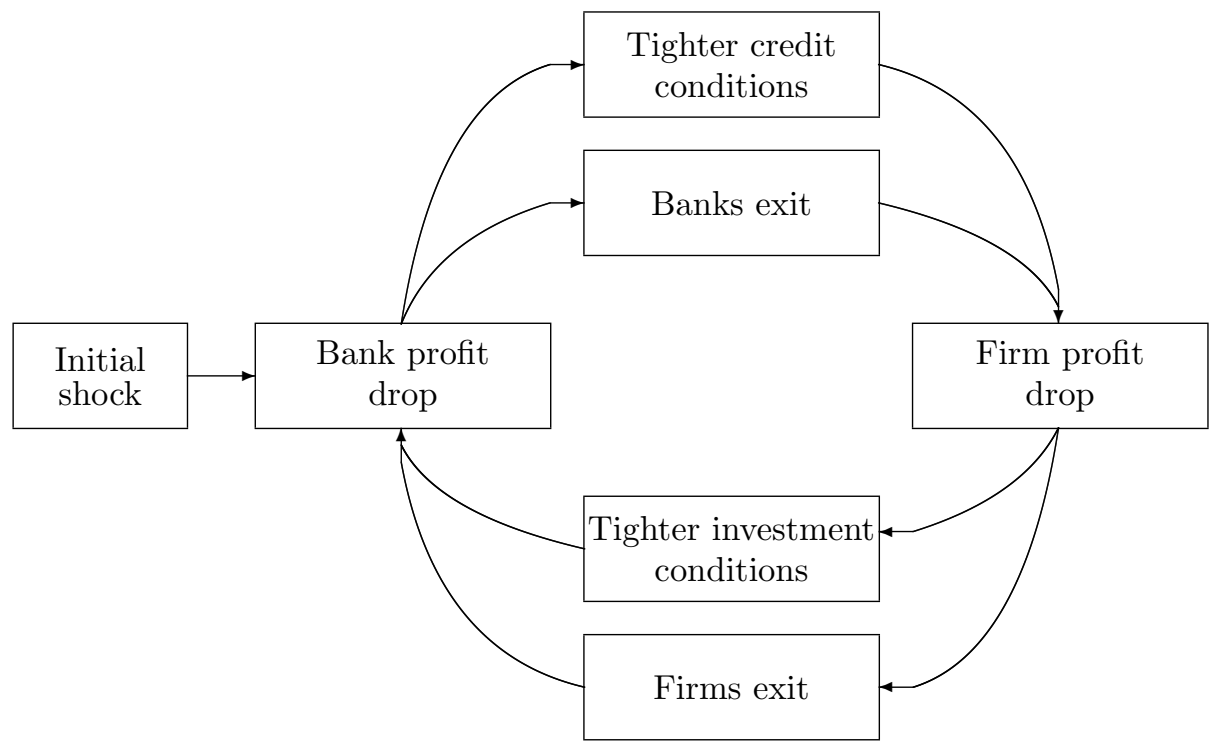

a more diversified financial system. In this paper, the strategic complementarity between financing production and aggregate investment emerges through the free entry conditions of entrepreneurs and bank managers and the consumption-saving decision of the representative investor. If the number of banks increases, there is more bank competition and the profit of entrepreneurs increases; for the free entry condition of entrepreneurs to hold, there needs to be more entrepreneurs competing for financing. Reciprocally, if the number of entrepreneurs increases, banks make higher profits and the entry of new banks brings expected profits back to the free entry level. Moreover, the consumption-saving decision of the representative investor acts as an amplification mechanism: the more firms and financial intermediaries, the better it is to save for later consumption. Greenwood and Jovanovic (1990); Obstfeld (1994); Acemoglu and Zilibotti (1997) study the dynamic properties of an economy with endogenous diversification. In these papers, a virtuous circle occurs from better diversification to more 
risk-taking and higher returns, and from higher wealth to better diversification. In Ciccone and Matsuyama (1996), the free entry of endogenous specialized "input" intermediaries is related to "initial conditions." Here, the virtuous circle goes through banking competition: more competition among financial intermediaries leads to more entrepreneurship entry and better investment opportunities while better investment opportunities allow the financial sector to thrive.

I.3. Credit constraint and policy. Bernanke and Gertler (1989, 1990); Holmstrom and Tirole (1997) emphasize the importance of credit constraints for economic activity. Because of moral hazard, the capital of entrepreneurs and bank managers is key in determining how much they can borrow from risk-neutral investors. Instead of assuming credit constraints, this paper focuses on the supply of capital from risk-averse investors. Endogenous constraints emerge on how much entrepreneurs and banks can borrow which in turn affects economic activity. In particular, these constraints depend on interest-rate policy which affects the composition of riskfree and risky securities in the portfolio of risk averse investors. Another difference with these papers is the emphasis on the complementarities that link the decisions of banks and firms and lead to contagion effects. Bolton and Freixas (2006) study the effect of monetary policy on the composition of aggregate claims using a general equilibrium model with asymmetric information on the types of banks. Allen and Gale (2000, chapter 8) present a model in which competition induces risk-shifting and therefore affects the stability of the economy. ${ }^{8}$ Risk-shifting behavior provides a natural motivation for regulation. This paper focuses on monetary policy and shows that the stability of the economy is related to the the profitability of banks and firms, not to risk-shifting or moral hazard.

\footnotetext{
${ }^{8}$ Boyd and De Nicolo (2005) discuss the robustness of the results. Carletti (2005, forthcoming) surveys the existing literature on bank competition and stability. Beim and Calomoris (2001) review the determinants of banking crises in emerging markets.
} 


\section{FiguRE 2 .}

Timing. The figure shows the timing of the decisions of the monetary authority (central bank), the representative investors, the bank mangers and the entrepreneurs.

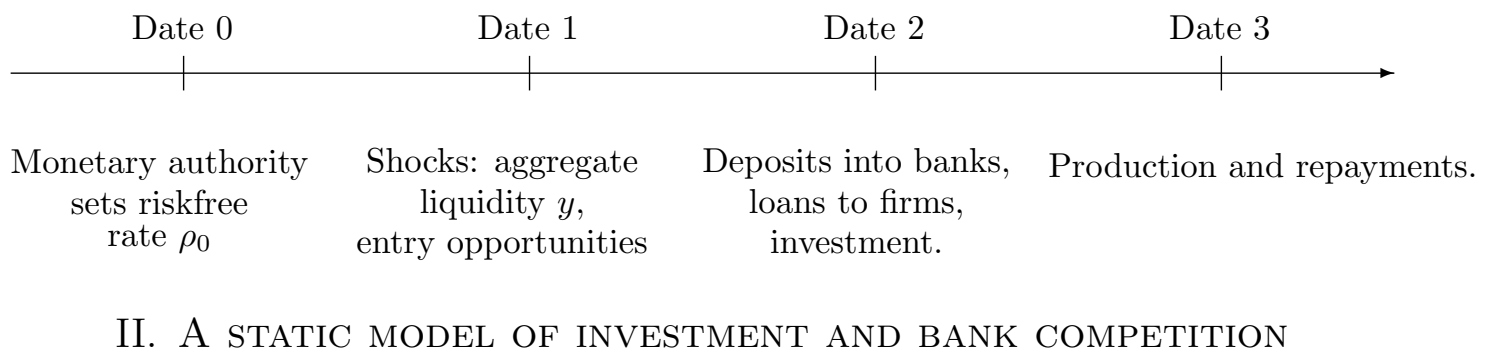

The model has four dates. At date 0 , the central banks sets the riskfree rate $\rho_{0}$. At date 1 , shocks affect aggregate investment or the entry of banks and firms. At date 2, entry decisions are made, the share of the savings of a risk-averse representative investor is channeled to entrepreneurs through banks and the rest is invested in a riskfree security. The return on the risky investments depends on the competition between firms to raise external finance and the competition between banks to charge the services for financial intermediation. At date 3 , production takes place, entrepreneurs repay their bank, bank managers repay the deposits and the representative investor consumes. The model is solved by backward induction. Section II.1 describes the uncertainty and the risk-averse investor decisions. Section II.2 describes the firm and bank decisions. Section II.3 introduces the condition for free entry in banking and industries. Section II.4 characterizes the equilibria of the model.

II.1. Uncertainty and the supply of capital. Identical investors with aggregate capital $Y$ have log-preferences and choose between immediate consumption $c$ and investment for future consumption. They can invest in a riskfree security yielding the return $\rho_{0}$. They can also invest in a set of risky projects that collectively generates revenues with probability $p<1 .^{9}$ There is an endogenous number $M$ of risky projects per sector and investing in a

\footnotetext{
${ }^{9}$ In this model, market incompleteness is exogenous.
} 
sector is equivalent to buying a basic Arrow security that pays in only one state of nature. We assume an infinite countable set of equally likely risky states represented by the unit interval and projects in sector $\varphi \in[0,1]$ pay a positive return only in state $\varphi$ and nothing in any other state. Each risky project indexed by $(\varphi, m) \in[0,1] \times[1, M]$ promises a deposit rate $\rho(\varphi, m)$ if it generates revenue and by limited liability, zero otherwise. ${ }^{10}$ The objective function of investors is then

$$
\log (c)+\beta(1-p) \log \left(\rho_{0} k_{0}\right)+\beta p \int_{0}^{1} \log \left[\rho_{0} k_{0}+\sum_{m=1}^{M} \rho(\varphi, m) k(\varphi, m)\right] d \varphi
$$

where $\beta$ is the discount rate and $\left\langle k_{0}, k(\varphi, m)\right\rangle$ are the investments in the riskfree and risky securities. The budget constraint is

$$
c+k_{0}+\sum_{m=1}^{M} \int_{0}^{1} k(\varphi, m) d \varphi=Y
$$

Because of the logarithmic preferences, the first period consumption is $c=Y /(1+\beta)$. Denote $y=\beta Y /(1+\beta)$ as the disposable income in the later period. Using the firstorder condition of the investors, the supply of capital $k=K(\rho)$ for investment in a project $(\varphi, m) \in[0,1] \times[1, M]$ is an increasing concave function in the return $\rho$

$$
K(\rho)=p y-\frac{\rho_{0} k_{0}+\sum_{m^{\prime} \neq m} \rho\left(\varphi, m^{\prime}\right) k\left(\varphi, m^{\prime}\right)}{\rho} .
$$

By symmetry, all the projects in a sector promise the same rate of return and there is investment in sector $\varphi$ only if $\rho \geq \frac{\rho_{0} k_{0}}{p y} \equiv \rho^{*}$. The elasticity of the supply of capital:

$$
\epsilon(\rho)=\frac{\rho K^{\prime}(\rho)}{K(\rho)}=\left[\frac{\rho}{\left(\rho^{*}+\frac{\sum_{m^{\prime} \neq m} \rho\left(\varphi, m^{\prime}\right) k\left(\varphi, m^{\prime}\right)}{p y}\right)}-1\right]^{-1}
$$

\footnotetext{
${ }^{10}$ This formulation is equivalent to that of Acemoglu and Zilibotti (1997) and has the property that an infinitesimal investment pays a non-infinitesimal amount with an infinitesimal probability so that the return is well-defined. If a portfolio consists of an equiproportional investment $K_{\Phi}$ in all projects in sectors $\varphi \in \Phi \subseteq[0,1]$, then the portfolio pays $\int \rho(\varphi) d \varphi$ with probability $p|\Phi|$ and nothing with probability $1-p|\Phi|$.
} 


\section{FIGURE 3.}

Investment opportunities and pricing. A risk-averse representative investor can invest in a riskfree security for the return $\rho_{0}$ or in banks for the risky return $\rho$. Banks in turn provide loans to firms for a return $\rho(1+\xi)$ where $\xi$ is the intermediation markup.

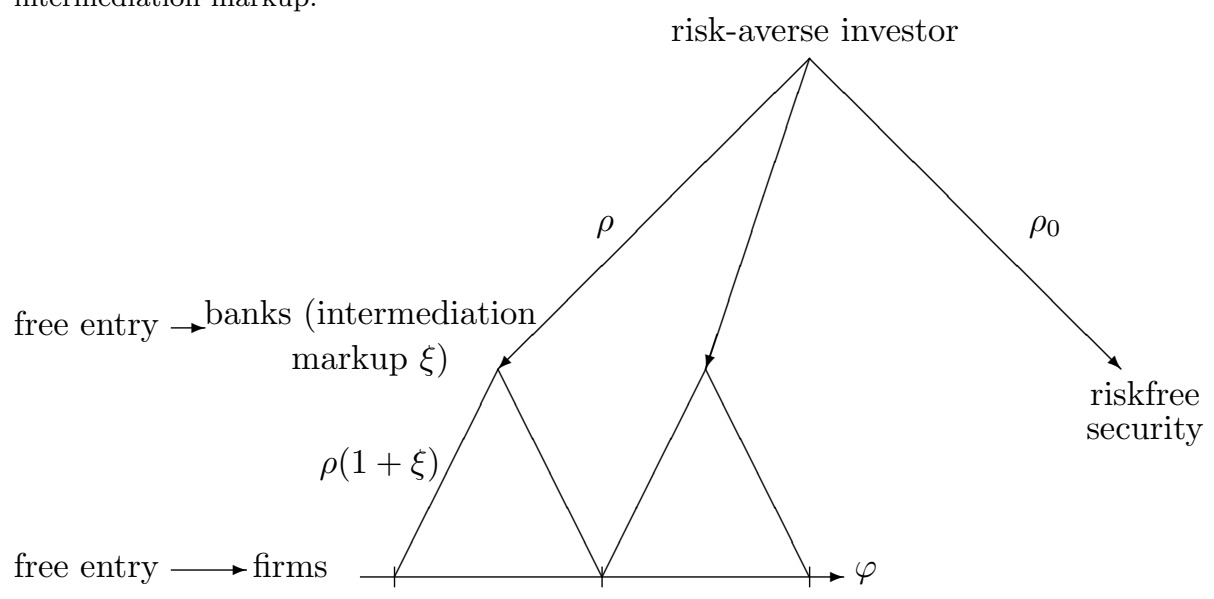

is increasing in the number of firms $M$ and in the riskfree investment $\rho_{0} k_{0}$ (or equivalently in the floor rate $\left.\rho^{*}\right) .{ }^{11}$ Similar to Acemoglu and Zilibotti (1997); Martin and Rey (2004); Winton (1997), because of the structure of uncertainty, each project in each industry matters for the risk-averse investors and the elasticity of the supply of capital is finite: $\epsilon(\rho)<+\infty$. The elasticity is larger when the investors are better diversified with more riskfree investment (ie. with a higher $\rho^{*}=\frac{\rho k_{0}}{p y}$ ) or when within a sector, the number of projects $M$ is larger.

\section{II.2. Firm and bank decisions and the demand for capital.}

Firms. The projects ("firms") are run by risk-neutral entrepreneurs. The production technology has constant returns and they set the return $\rho$ to maximize

$$
\pi_{e}=A K(\rho)-\rho(1+\xi) K(\rho)
$$

\footnotetext{
${ }^{11}$ This setup is related to international trade models with heterogeneous firms. In particular, the fact that the elasticity of the supply of capital is non-constant is related to Melitz and Ottaviano (2008).
} 
where $\xi>0$ is an intermediation markup fixed by the bank transferring funds from the investors to the firm. The first-order condition for this problem is

$$
\frac{\frac{A}{1+\xi}-\rho}{\rho}=\frac{1}{\epsilon(\rho)}
$$

where $\epsilon(\rho)$ is the elasticity defined in Equation (2.2). This yields the equilibrium return

$$
\rho(\xi)=\frac{A}{1+\xi}\left[\frac{\sqrt{\frac{\rho^{*} M(1+\xi)}{A}+\left(\frac{M-1}{2}\right)^{2}}+\frac{M-1}{2}}{M}\right] .
$$

The equilibrium interest rate is increasing in the productivity $A$, in number of firms $M$ and in the minimum rate $\rho^{*}=\frac{\rho_{0} k_{0}}{p y}$ related to the riskfree security and decreasing in the intermediation markup $\xi$. In particular $1>\frac{\rho(1+\xi)}{A}>\frac{\rho^{*}(1+\xi)}{A}$. The productivity $A$ is the maximum technological rate that firms can promise and the promised rate $\rho$ is closer to $A$ when there is more competition between firms (higher $M$ ), when there is more competition between banks (lower $\xi$ ) or when the floor rate $\rho^{*}$ is larger. Denote $\pi_{e}$ the profit of the entrepreneurs. The investment decision leads to

$$
\begin{aligned}
\pi_{e}(\xi) & =\frac{p A y}{M^{2}}\left[1-\frac{\rho^{*}}{\rho(\xi)}\right]^{2} \\
k(\xi) & =\frac{p y}{M}\left[1-\frac{\rho^{*}}{\rho(\xi)}\right] .
\end{aligned}
$$

Banks. There is a finite number of financial intermediaries ("banks") indexed by $n$, uniformly distributed on $[0,1] .{ }^{12}$ They are separated by the endogenous distance $2 z$ so that there are $N=\frac{1}{2 z}$ banks in equilibrium. Each bank is specialized in providing financial services close to its location. If a bank is located in $\varphi_{n}$, it incurs the cost $f_{\varphi}\left|\varphi-\varphi_{n}\right|$ when lending to a firm located in $\varphi$. By symmetry, a bank serves all firms with a distance $z \cdot{ }^{13} \mathrm{~A}$ lower intermediation cost $f_{\varphi}$ makes bank competition tougher while a larger $f_{\varphi}$ increases

\footnotetext{
${ }^{12}$ In this paper, we focus on symmetric banks. Vogel (2008) studies a model of spatial competition in which asymmetric agents face location decisions.

${ }^{13}$ We ignore "border effects": the segment $[0,1]$ is a circle.
} 


\section{Figure 4.}

Spatial bank competition setup. The profit of a bank $\pi_{b}$ is its revenues minus the intermediation cost. In the monopoly region, the profit of a bank is $\pi_{b}=f_{\varphi}\left(z_{m}-\varphi\right)$. In the contested region, the markup is set that the closest banks makes zero profit and the profit of a bank is $\pi_{b}=f_{\varphi}[(2 z-\varphi)-\varphi]$.

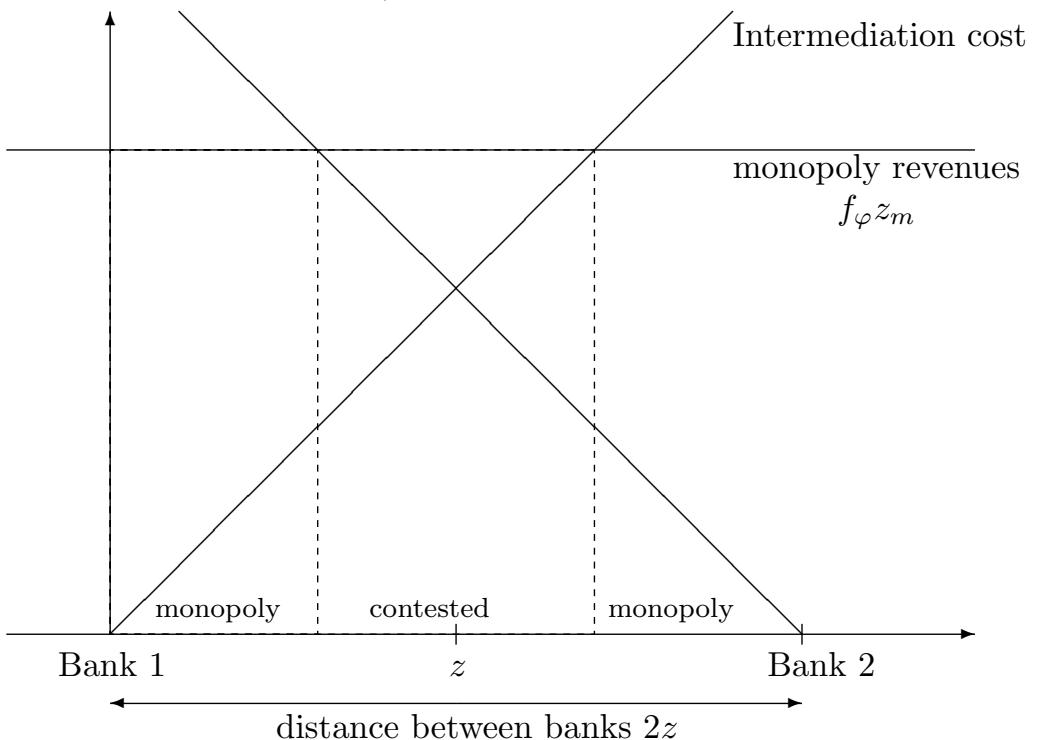

"segmentation" and softens bank competition. Subject to the contestability by other banks,

a bank manager maximizes its revenues $M \xi \rho(\xi) k(\xi)$ for each industry $\varphi$. The monopoly markup $\hat{\xi}_{m}$ is set such that $\xi$ maximizes the bank revenues

$$
\hat{\xi}_{m}=\operatorname{argmax} \operatorname{py} \xi\left[\rho(\xi)-\rho^{*}\right] .
$$

Otherwise the markup $\xi$ is set up so that the closest bank makes zero profit

$$
\operatorname{py} \xi\left[\rho(\xi)-\rho^{*}\right]-f_{\varphi}(2 z-\varphi)=0 .
$$

Figure 4 represents spatial competition setup between banks.

Lemma 1 (intermediation markup pricing). The intermediation markup $\xi$ for firms located in $\varphi \in[0, z]$ is

$$
\xi\left(\varphi \mid \rho^{*}, z, M\right)=\left\{\begin{array}{lll}
\hat{\xi}_{m}\left(\rho^{*}, M\right) & \text { if } \varphi \in\left[0,2 z-z_{m}\left(\rho^{*}, M\right)\right] & \text { monopoly loan, } \\
\hat{\xi}\left(\varphi \mid \rho^{*}, z, M\right) & \text { if } \varphi \in\left[2 z-z_{m}\left(\rho^{*}, M\right), z\right] & \text { contested loan. }
\end{array}\right.
$$




\section{FiguRE 5.}

Bank competition regimes. The figure summarizes the information of Lemma 1 and Corollary 1 and shows the markup pricing for different half-distance between banks $z$ and different distance to banks $\varphi$. The more banks there are (ie. the smaller the distance $2 z$ between banks), the more likely loans are to be contested.

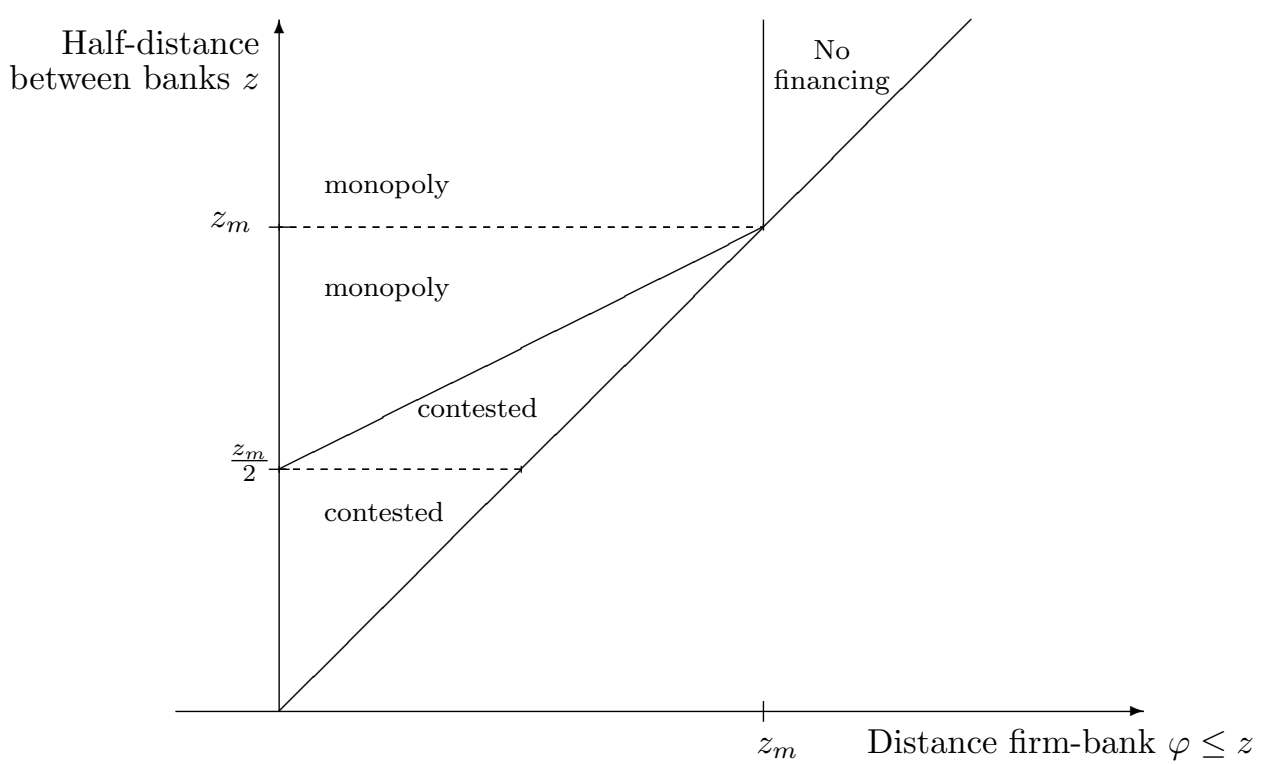

where $f_{\varphi} z_{m}\left(\rho^{*}, M\right)=\operatorname{py} \hat{\xi}_{m}\left(\rho^{*}, M\right)\left[\rho\left(\hat{\xi}_{m}\left(\rho^{*}, M\right)\right)-\rho^{*}\right]$ is the monopoly profit of a bank. The markup pricing $\xi\left(\varphi \mid \rho^{*}, z, M\right)$ is decreasing in the distance $\varphi \in[0, z]$ and in the number of firms $M$ and increasing in the floor rate $\rho^{*}$ and the distance between banks z. Bank monopoly profit decreases in $\rho^{*}$ and increases in $M$.

Proof. See Appendix.

Corollary 1. If $z>z_{m}\left(\rho^{*}, M\right)$, no loan is ever contested by a competitor. Otherwise some loans are contested, and if $z<z_{m}\left(\rho^{*}, M\right) / 2$, all loans being contested.

Competition between banks brings markup pricing down, either when a firm is further away from a bank $(\varphi \in[0, z]$ increases) or when banks are closer to each other ( $z$ decreases). When the floor rate $\rho^{*}$ increases (ie. when there is more riskfree investment $k_{0}$ ), the profit of banks decreases and the loan markup is increased to counterbalance the drop. When the 


\section{FIGURE 6.}

Intermediation markup and investor return. This figure shows the equilibrium intermediation markup $\xi$ (left panel) and investor return $\rho$ (right panel) as a function of the distance between a project and a bank $\varphi \in[0, z]$ for two competition regimes (high competition regime $z<z_{m} / 2$ and low competition regime $z \in\left[z_{m} / 2, z_{m}\right] . \xi$ and $\rho$ are solutions of cubic equations (see Appendix). Parameters: $\delta_{e}=.11, \delta_{b}=.11, \delta_{\varphi}=1.1,1-p=.2, \rho_{0}=1.08, A=3.6$. High competition regime: $M=7, N=4.2$. Low competition regime: $M=5.2, N=3.4$.
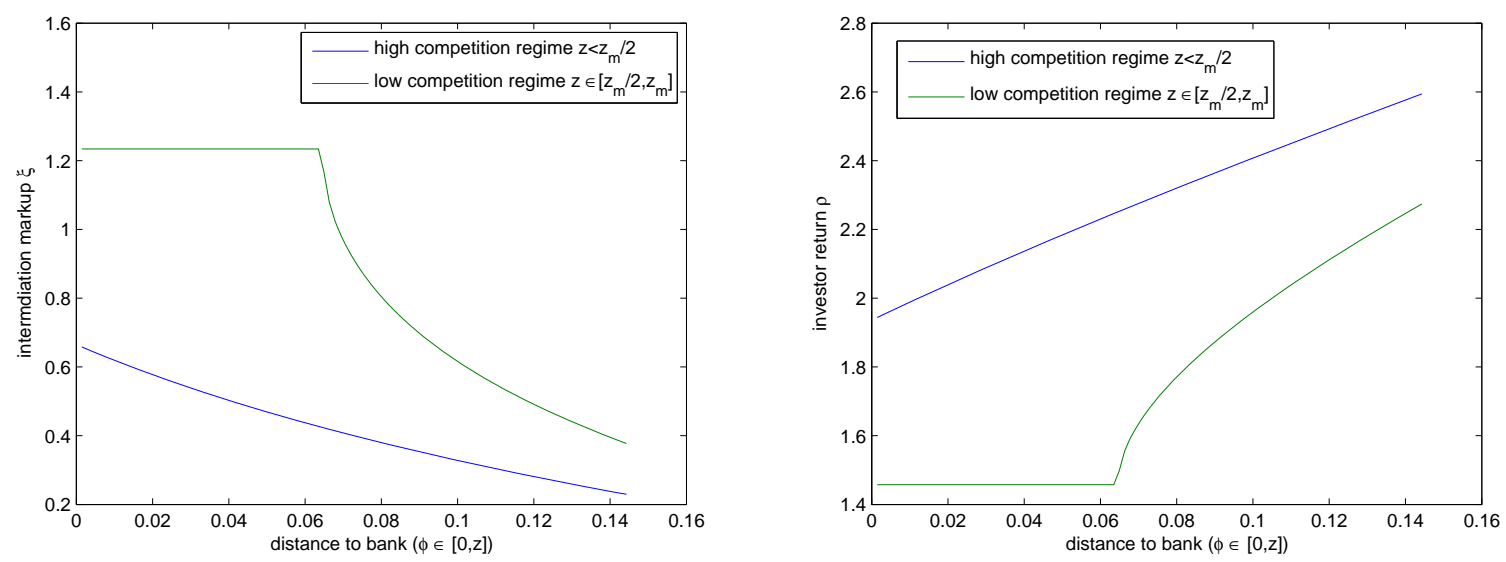

number of firms $M$ increases, bank profit increases and the loan markup it needs to charge decreases. The profit of a bank is ${ }^{14}$

$$
\pi_{b}=2 f_{\varphi} M \int_{0}^{z}\left[\min \left(z_{m}\left(\rho^{*}, M\right), 2 z-\varphi\right)-\varphi\right] d \varphi \equiv 2 f_{\varphi} J\left(\rho^{*}, z, M\right)
$$

where $J\left(\rho^{*}, z, M\right)=M \int_{0}^{z}\left[\min \left(z_{m}\left(\rho^{*}, M\right), 2 z-\varphi\right)-\varphi\right] d \varphi$.

Corollary 2 (investment pricing). The investment return $\rho$ is increasing in the distance $\varphi$ between a firm and its bank, in the floor rate $\rho^{*}$ and in the number of firms $M$ and decreasing in the distance between banks $2 z$.

When there is more competition (either because the number of firms increases or the distance between banks decreases, or because a firm is closer to the mid-distance between banks), the interest rate $\rho$ increases and gets closer to the maximum technological rate $A$.

\footnotetext{
${ }^{14}$ This is equivalent to $\pi_{b}=2 f_{\varphi} M\left[z^{2} 1_{\left\{z \leq z_{m} / 2\right\}}+\left(z^{2}-\frac{\left(2 z-z_{m}\right)^{2}}{2}\right) 1_{\left\{z \in\left[z_{m} / 2, z_{m}\right]\right\}}+\frac{z_{m}^{2}}{2} 1_{\left\{z \geq z_{m}\right\}}\right]$.
} 
II.3. Free entry and aggregation. There is a large pool of prospective entrepreneurs and bank managers wishing to enter. To do so, they pay a fixed entry cost $f_{e}$ for entrepreneurs, and $f_{b}$ for bank managers before knowing their location. The timing involves the entry of firms and banks, the investment of entrepreneurs, the deposits of the representative investor:

- Stage 0. Bank managers and entrepreneurs make their entry decisions and draw their location.

- Stage 1. Bank managers set their lending schedule, ie bank $n$ offers the entrepreneur running the project $\varphi$ the lending rate $\hat{\rho}_{n}(k, \varphi)$ for investment $k$.

- Stage 2. Given the lending schedules of the banks $\left\{n \in[1, N]: \hat{\rho}_{n}(k, \varphi)\right\}$, the entrepreneur running the project $\varphi$ chooses a bank and sets the investment size $k$.

- Stage 3. Bank managers raise deposits by offering the deposit rate $\rho(k, \varphi)$ to the representative investor if firm $\varphi$ generates revenue. The investor consumes $c$.

- Stage 4. Projects generate revenues, entrepreneurs repay their bank or go bankrupt, bank managers repay the deposits and the representative investor consumes.

In what follows we normalize the costs for convenience by the maximum expected repayment $p A y: \kappa_{e}=\sqrt{\frac{f_{e}}{p A y}}, \kappa_{b}=\frac{f_{b}}{2 p A y}$ and $\kappa_{\varphi}=\frac{f_{\varphi}}{p A y}$. The free entry condition for banks impose $\pi_{b}=f_{b}$ and using Equation (2.5), we have

$$
\frac{\kappa_{b}}{\kappa_{\varphi}}=\frac{f_{b}}{2 f_{\varphi}}=J\left(\rho^{*}, z, M\right),
$$

where $J\left(\rho^{*}, z, M\right)=M \int_{0}^{z}\left[\min \left(z_{m}\left(\rho^{*}, M\right), 2 z-\varphi\right)-\varphi\right] d \varphi$. The entrepreneur free entry condition imposes $f_{e}=\frac{1}{z} \int \pi_{e}(\varphi) d \varphi$ and using profit equation $(2.3)$ with $I_{i}\left(\rho^{*}, z, M\right)=$ $\sqrt[i]{\frac{1}{z} \int_{0}^{z}\left(1-\frac{\rho^{*}}{\rho[\xi(\varphi)]}\right)^{i} d \varphi}$, we have

$$
\kappa_{e}=\sqrt{\frac{f_{e}}{p A y}}=\frac{I_{2}\left(\rho^{*}, z, M\right)}{M} .
$$


Similarly, using the investment equation (2.4), the aggregate budget constraint is $y=k_{0}+$ $\operatorname{py} I_{1}\left(\rho^{*}, z, M\right)$ or

$$
1-\frac{p \rho^{*}}{\rho_{0}}=p I_{1}\left(\rho^{*}, z, M\right)
$$

Lemma 2. The expected profit of entrepreneurs $\left(\frac{I_{2}\left(\rho^{*}, z, M\right)}{M}\right)^{2}$ is decreasing in the floor rate $\rho^{*}$, the distance between firms $2 z$ and the number of firms $M$. The expected profit of bank managers $2 f_{\varphi} J\left(\rho^{*}, z, M\right)$ is decreasing in the floor rate $\rho^{*}$ and increasing in the distance between banks $2 z$ and the number of firms $M$. Aggregate investment $p y I_{1}\left(\rho^{*}, z, M\right)$ is decreasing in the floor rate $\rho^{*}$ and the distance between banks $2 z$ and increasing in the number of firms $M$.

Proof. See Appendix.

When the intermediation cost $f_{\varphi}$ increases, the bank competition is softer and the financial markup $\xi$ goes up, increasing the profit of banks but decreasing the profit of entrepreneurs and aggregate investment.

II.4. Equilibrium determination. The previous section presented a tractable model of bank competition in which the decisions of firms and banks are aggregated in closed-form and yield two free entry conditions (for entrepreneurs and bank managers) and a budget constraint. The equilibrium is characterized by three equations in the three unknown variables $\left\langle\rho^{*}, z, M\right\rangle$. The budget constraint (2.8) is used to eliminate the floor rate $\rho^{*}$ and focus on a two-equation-two-unknown problem in the number of firms $M$ and the number of banks $N=\frac{1}{2 z}$. The parameters are normalized entry $\operatorname{costs} \delta_{e}, \delta_{b}$, the distance cost $\delta_{\varphi}$, the riskfree rate $\rho_{0}$, the technological productivity $A$, the recession probability $1-p$, and the available capital $y$. 
Equilibrium riskfree allocation. Equation (2.8) characterizes the general equilibrium riskfree allocation

$$
1-\frac{p \rho^{*}}{\rho_{0}}=p I_{1}\left(\rho^{*}, z, M\right)
$$

The left-hand side $1-p \rho^{*} / \rho_{0}$ decreases from 1 in $\rho^{*}=0$ to 0 in $\rho^{*}=\rho_{0} / p$. The function $\rho^{*} \mapsto p I_{1}\left(\rho^{*}, z, M\right)$ decreases from $p \in[0,1]$ in $\rho^{*}=0$ to 0 in $\rho^{*}=A>\rho_{0} / p$. Since the two functions are continuous they intersect in at least one value of $\rho^{*}$ which is unique.

Lemma 3. The floor rate $\rho^{*}(z, M)$ (and equivalently the riskfree investment $k_{0}=p y \rho^{*} / \rho_{0}$ ) is increasing in the distance between banks $z$ and decreasing in the number of firms $M$.

Proof. See the Appendix for technical details on the implicit function $\rho^{*}(z, M)$.

When there is more banking competition (the distance between banks $z$ is smaller) or when the number of firms $M$ is higher, investment in the risky sector is more efficient and the riskfree investment decreases as well as the floor rate $\rho^{*}$. When the riskfree rate $\rho_{0}$ is larger, there is more riskfree investment $k_{0}$ and the floor rate $\rho^{*}$ is larger. Similarly when the banking market is more segmented (higher intermediation cost $f_{\varphi}$ ), there is less banking competition and the distortionary financial markups are higher, making risky investment less attractive and leading to an increase in the riskfree investment $k_{0}$.

Equilibrium bank entry. In this section, the equilibrium riskfree allocation is used to determine the number of banks $N$ (or equivalently the distance between banks $2 z=\frac{1}{N}$ ) as a function of the number of firms $M$. More precisely, the equilibrium monopoly profits are pinned down by the allocation of riskfree capital $z_{m}\left(\rho^{*}(z, M), M\right)$ and by the banking free entry condition (2.7). We have

$$
\frac{\kappa_{b}}{\kappa_{\varphi}}=J\left(\rho^{*}(z, M), z, M\right) .
$$


First, when the distance $2 z$ between banks increases, the floor rate $\rho^{*}(z, M)$ increases and the monopoly profit $z_{m}\left(\rho^{*}(z, M), M\right)$ decreases. Similarly, when the number of firms $M$ increases, the floor rate decreases and monopoly profits increase. Second, when the monopoly profits $z_{m}$ are larger or when the number of firms $M$ is larger, more banks enter, and the distance between banks $z$ decreases. Taken together, the right-hand side of (2.9) is increasing in $M$ and decreasing in $z$ which implies and that in equilibrium more banks enter when there are more firms.

Lemma 4. There exists $M_{\min }^{b}$ such that for all $M \geq M_{\min }^{b}$, the Equation (2.9) defines the implicit function $N^{b}(M)$ is increasing in $M$.

Proof. See Appendix.

The implicit function $N^{b}(M)$ is decreasing in the entry cost $\kappa_{b}$, the riskfree rate $\rho_{0}$, and the recession probability $1-p$ and increasing in the intermediation cost $\kappa_{\varphi}$.

Equilibrium firm entry. The equilibrium riskfree allocation is now used to determine the number of firms $M$ as a function of the number of banks $N$ (or equivalently the distance between banks $\left.2 z=\frac{1}{N}\right)$. More precisely we rewrite (2.7) as

$$
\kappa_{e} M=I_{2}\left(\rho^{*}(z, M), z, M\right)
$$

where $\kappa_{e}$ is the normalized firm entry $\operatorname{cost} \kappa_{e}=\sqrt{\frac{f_{e}}{p A y}}$. The right-hand side is increasing in the number of firms $M$ and decreasing in the distance between banks $z$.

Lemma 5. There exists $N_{\min }^{e}$ such that for all $N \geq N_{\min }^{e}$, these two functions have an intersection and the implicit function $M^{e}(N)$ is increasing in $N$.

Proof. See Appendix.

The implicit function $M^{e}(N)$ is decreasing in the entry cost $\kappa_{e}$, the intermediation cost $\kappa_{\varphi}$, and the riskfree rate $\rho_{0}$ in the recession probability $1-p$. 
Number of firms and banks in equilibrium.

Proposition 1 (multiple equilibria). In general there are three equilibria: (i) a production equilibrium with many firms and many banks; (ii) an intermediate production equilibrium with few firms and banks; (iii) and a no-production equilibrium (no firm and bank entry). The production equilibrium is more likely to exist if the entry costs $\delta_{e}, \delta_{b}$, the free rate $\rho_{0}$ or the crisis probability $1-p$ are lower.

In the production equilibrium, the number of firms and banks is decreasing in the entry $\kappa_{e}$ and $\kappa_{b}$, in the riskfree rate $\rho_{0}$ and in the recession probability $1-p$.

Remark (approximation): when there are a lot of firms and banks, we have $I_{1}\left(\rho^{*}, z, m\right)=$ $I_{2}\left(\rho^{*}, z, m\right) .{ }^{15}$ This approximation works very well for large numbers of firms and banks (typically the good equilibria). From this assumption, we find that $p \kappa_{e} M=1-\frac{p \rho^{*}}{\rho_{0}}$. The equilibrium firm number is then given by

$$
\kappa_{e} M=I_{1}\left[\frac{\rho_{0}\left(1-p \kappa_{e} M\right)}{p}, Z_{b}\left(z_{m}\left(\frac{\rho_{0}\left(1-p \kappa_{e} M\right)}{p}, M\right)\right), M\right]
$$

\section{MONETARY POLICY AND THE EFFECT ON EFFICIENCY AND STABILITY}

Section III.1 looks at the stability properties of the equilibria. Section III.2 discusses comparative statics on output and welfare and emphasize the first main result of this paper: a policymaker maximizing the static welfare of investors aims at increasing the riskfree rate. Section III.3 discusses policy implications and introduces the second result: by increasing the riskfree rate, the buffers of the economy are smaller and it makes the economy more vulnerable to aggregate and idiosyncratic shocks.

\footnotetext{
${ }^{15} I_{2}\left(\rho^{*}, z, M\right)=\sqrt{\frac{1}{z} \int_{0}^{z}\left(1-\frac{\rho^{*}}{\rho(\xi(\varphi))}\right)^{2} d \varphi}=I_{1}\left(\rho^{*}, z, M\right) \sqrt{1+\frac{D\left(\rho^{*}, z, M\right)}{I_{1}\left(\rho^{*}, z, M\right)}}$ where $D\left(\rho^{*}, z, M\right)$ is the standard deviation of $1-\frac{\rho^{*}}{\rho(\xi(\varphi))}$ which is small if $M$ and $N$ are large because competition (between firms or between banks) decreases the dispersion in rates.
} 
III.1. Properties of the equilibria and calibration. After illustrating the equilibria with a set of parameters, we analyze the properties of the equilibria (welfare and stability).

Calibration. The equilibrium can be solved using five normalized parameters $\left\langle\delta_{e}, \delta_{b}, \delta_{\varphi}, p, \rho_{0}, A\right\rangle$ : three costs (entrepreneur entry cost $\delta_{e}=\sqrt{\frac{f_{e}}{p A y}}$, bank manager entry cost $\delta_{b}=\frac{f_{b}}{p A y}$ and intermediation $\left.\operatorname{cost} \delta_{\varphi}=\frac{f_{\varphi}}{p A y}\right)$; the recession probability $1-p$; the riskfree rate $\rho_{0}$; and the productivity $A$.

We set the following parameters

- costs: $\delta_{e}=.11, \delta_{b}=.11, \delta_{\varphi}=1.1$,

- recession probability $1-p=.2$,

- riskfree rate: $\rho_{0}=1.08$,

- productivity: $A=3.6$.

Figure 7 represents the free entry conditions and the equilibria. The production equilibrium involves $N=4.2$ banks and $M=7$ firms. ${ }^{16}$ The equilibrium floor rate is $\rho^{*}=.5357$ which implies a riskfree share $k_{0} / y=0.3818$ in the portfolio.

Stability and discussion of the dynamics. In this section we discuss the stability of the equilibria by studying off-equilibrium dynamics in Figure $9 .{ }^{17}$ If the numbers of firms and banks $(N, M)$ are above (below) the firm free entry condition represented by the blue curve on Figure 9, then firms make negative (positive) profits and there too many (few) firms for the number of banks: some firms should exit (enter), leading to a decrease (increase) in $M$, represented by an arrow down (up). Similarly, if $(N, M)$ is above (below) the bank free entry condition represented by the green curve, then banks make positive (negative) profits and

\footnotetext{
${ }^{16}$ Issues related to non-integer numbers of firms or banks are ignored.

17 "Off-equilibrium" situations take place when it is costly to adjust the number of firms or banks. Caballero and Hammour (1994) model the entry cost as depending on the rate of new firm creation. Another possibility is to put an upper bound on the creation rate of new firms and banks. In such cases, the numbers of firms and banks $(N, M)$ become state variables.
} 


\section{FIGURE 7 .}

Multiple equilibria in a setup with endogenous firm and bank entry. The blue curve is the firm free entry condition. It represents the number of firms $M$ wishing to enter for a given number of banks $N$. The green curve is the bank free entry condition. It represents the number of banks $M$ wishing to enter for a given number of firms $M$. Red curves represent the degree of competition. The upper red curve is the high competition boundary $z=z_{m}\left(\rho^{*}(z, M), M\right) / 2$ and the lower red curve is the no-competition boundary $z=z_{m}\left(\rho^{*}(z, M), M\right)$. The red circles are the two stable production and no-production equilibria. Parameters: $\delta_{e}=.11, \delta_{b}=.11, \delta_{\varphi}=1.1,1-p=.2, \rho_{0}=1.08, A=3.6$.

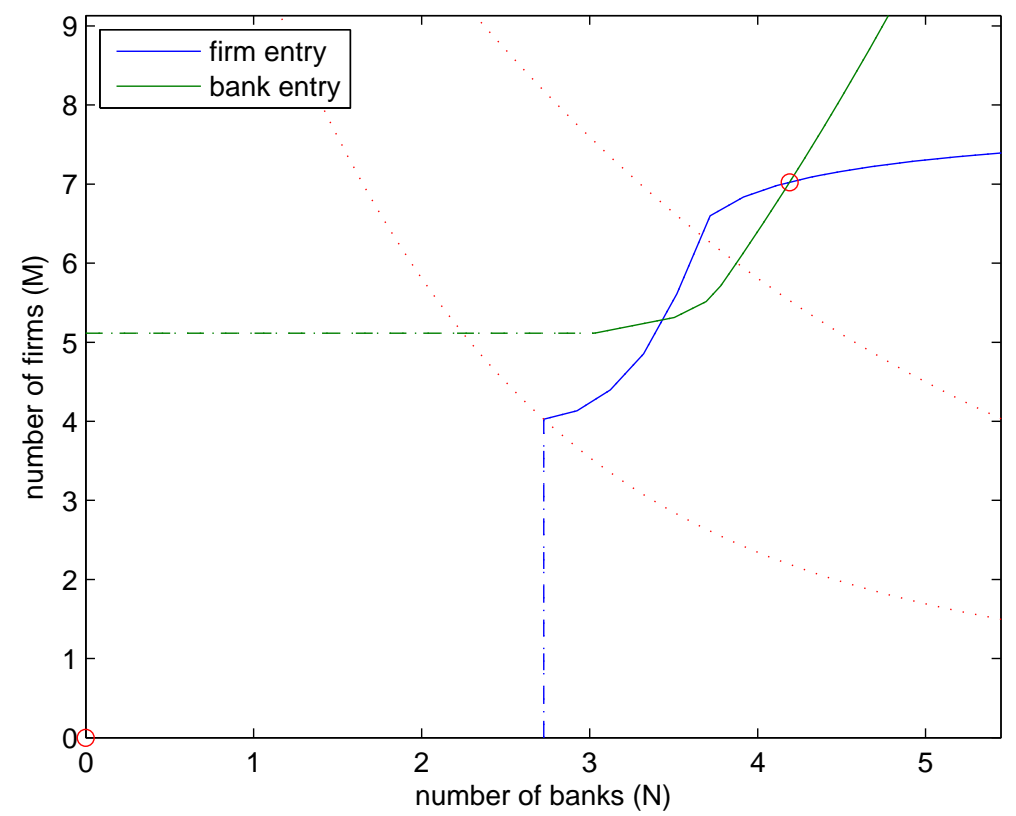

there too few banks for the number of firms: some banks should enter (exit), leading to an increase (decrease) in $N$, represented by a right (left) arrow.

This consideration implies that the no-production equilibrium and the production equilibrium with many firms and many banks are stable, while the intermediate equilibrium with few firms and few banks is unstable. Moreover there are two basins of attraction that determine the dynamics of the economy. If the initial conditions are such that there are enough firms and banks, the economy converges to the production equilibrium with many firms and banks. In theory, a policymaker could increase the speed of convergence by removing explicit or implicit barriers to entry for firms and banks by decreasing the cost of starting a new business (Djankov, La Porta, Lopez-de-Silanes, and Shleifer, 2002; Klapper, Laeven, 


\section{FiguRE 8.}

Multiple equilibria and off-equilibrium dynamics. Parameters: $\delta_{e}=.11, \delta_{b}=.11, \delta_{\varphi}=1.1,1-p=.2, \rho_{0}=1.08$, $A=3.6$.

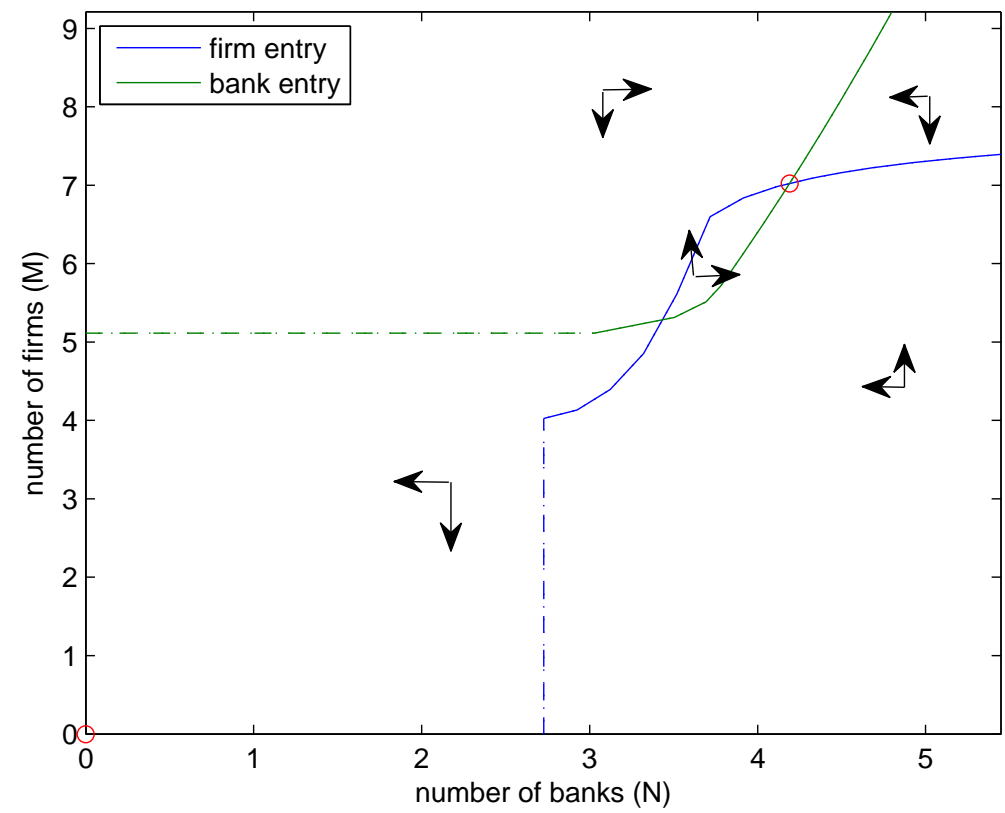

and Rajan, 2006), by allowing foreign banks and firms entry, and by the subsidization of financial "zombies" (Caballero, Hoshi, and Kashyap, 2008, forthcoming). In contrast, if the initial conditions are such that there are too few firms and banks, the economy converges to the no-production equilibrium with no firm or bank entry. In this case, the economy is stuck in a development trap. To solve the coordination problem and induce many entrepreneurs and bank managers to start simultaneously businesses, government planning or foreign aid might be necessary.

III.2. Comparative statics on output and welfare. This section studies comparative statics on output and welfare.

Lemma 6. The number of firms $M$, the number of banks $N$, the return $\rho$, the spread $\rho-\rho^{*}$ are increasing in the available capital $y$ and decreasing in the riskfree return $\rho_{0}$ while the floor rate is decreasing in $y$ and increasing in $\rho_{0}$. 
The entry of firms and banks depends not on the entry costs $f_{e}$ and $f_{b}$ once normalized by $p A y$ into the relative costs $\delta_{e}$ and $\delta_{b}$. A richer representative investor means that the entry costs are relatively lower, leading to more bank and firm entries. The increase in competition lead to a lower production markup $\frac{A-\rho}{A}$ and a lower financial markup $\xi$. Moreover, with more competition between firms and banks, risky investments become more desirable relative to the riskfree investment and the share or riskfree investment decreases (or equivalently the floor rate decreases). Reciprocally, a lower riskfree rate $\rho_{0}$ makes the riskfree investment more desirable and the number of firms and banks decreases. The welfare and total return are

$$
\begin{aligned}
U\left(\rho^{*}, z, M\right)-\log (p y) & =(1-p) \log \left(\rho^{*}\right)+\frac{p}{z} \int_{0}^{z} \log (\rho), \\
\bar{\rho}\left(\rho^{*}, z, M\right) & =p\left[(1-p) \rho^{*}+\frac{p}{z} \int_{0}^{z} \rho\right]
\end{aligned}
$$

These expressions show that the expected utility and return weigh growth (with probability $p$ ) against recession (with probability $1-p$ ). An actual decrease in capital takes place when $\frac{\rho_{0} k_{0}}{y}<1$

Lemma 7. The utility $U$ of the representative agent and the expected return $\bar{\rho}$ are higher in the good equilibrium (many firms, many banks) and lower in the no-production equilibrium (no firm and bank entry).

Proof. See Appendix.

The normalized repayment and utility are increasing in the floor rate $\rho^{*}$ and the number of firms $M$ and decreasing in the distance between banks $2 z{ }^{18}$ The volatility of the growth

\footnotetext{
${ }^{18}$ Steady state growth: If all the costs $f_{e}, f_{b}$ and $f_{\varphi}$ are proportional to the available capital $y$, then the growth rate of the economy does not depend on $y$.
} 
rate is

$$
\bar{\sigma}\left(\rho^{*}, z, M\right)=\underbrace{p(1-p)\left(\frac{1}{z} \int_{0}^{z} \rho d \varphi-\rho^{*}\right)^{2}}_{(1)}+\underbrace{\frac{p}{z} \int_{0}^{z}\left(\rho-\frac{1}{z} \int_{0}^{z} \rho d \varphi\right)^{2} d \varphi}_{(2)} .
$$

The effect of an increase in the number of firms $M$ on $\sigma$ depends on two opposite effects. Conditional on avoiding a crisis, it is possible to show that $\int_{0}^{z}\left(\rho-\frac{1}{z} \int_{0}^{z} \rho d \varphi\right)^{2} d \varphi$ decreases with the number of firms and banks. But as the number of firms and banks grows, there is less investment in the riskfree asset and $\rho^{*}$ decreases, so that the term $\left(\frac{1}{z} \int_{0}^{z} \rho d \varphi-\rho^{*}\right)^{2}$ increases. The effect of a downturn is stronger with more firms.

Lemma 8. The welfare $U$, the expected return $p \bar{\rho}$, the variance $\bar{\sigma}$ are increasing in the available capital $y$ and the riskfree rate $\rho_{0}$ and the Sharpe ratio $\bar{s}=\frac{\bar{\rho}}{\bar{\sigma}}$ is decreasing in $y$ and $\rho_{0}$.

If the investment by the representative investor is interpreted as the deposit (debt) funding of the banks and of the firms while the capital used to pay for the fixed costs is interpreted as equity, then bank leverage $L_{b}$ can be defined as the bank capital divided by the inside bank equity captured by the fixed cost $f_{b} \cdot{ }^{19}$

$$
L_{b}=\frac{p y I_{1}\left(\rho^{*}, z, M\right)}{N f_{b}}
$$

Similarly the firm leverage $L_{e}$ is the firm (expected) capital divided by the inside firm equity captured by the fixed cost $f_{e}$

$$
L_{e}=\frac{p y I_{1}\left(\rho^{*}, z, M\right)}{M f_{e}} .
$$

\footnotetext{
${ }^{19}$ In this interpretation, the debtholders (ie. the risk-averse investors) are more risk-averse than the (risk-neutral) entrepreneurs and bank managers.
} 


\section{FiguRE 9 .}

Bad macroeconomic shocks and policy response. The left panel represents the equilibrium conditions under a bad macroeconomic shock where the disposable capital has decreased by $8 \%$, or equivalently the normalized costs $\delta_{e}, \delta_{b}$ and $\delta_{\varphi}$ have increased by $8 \%$. The production equilibrium has disappeared. In the long-run (without policy response), the economy should regress to the no-production equilibrium. The right panel shows how a $5 \%$ decrease in the riskfree rate $\rho_{0}$ from 1.08 to 1.026 compensates the increase in normalized costs. The production equilibrium reappears.
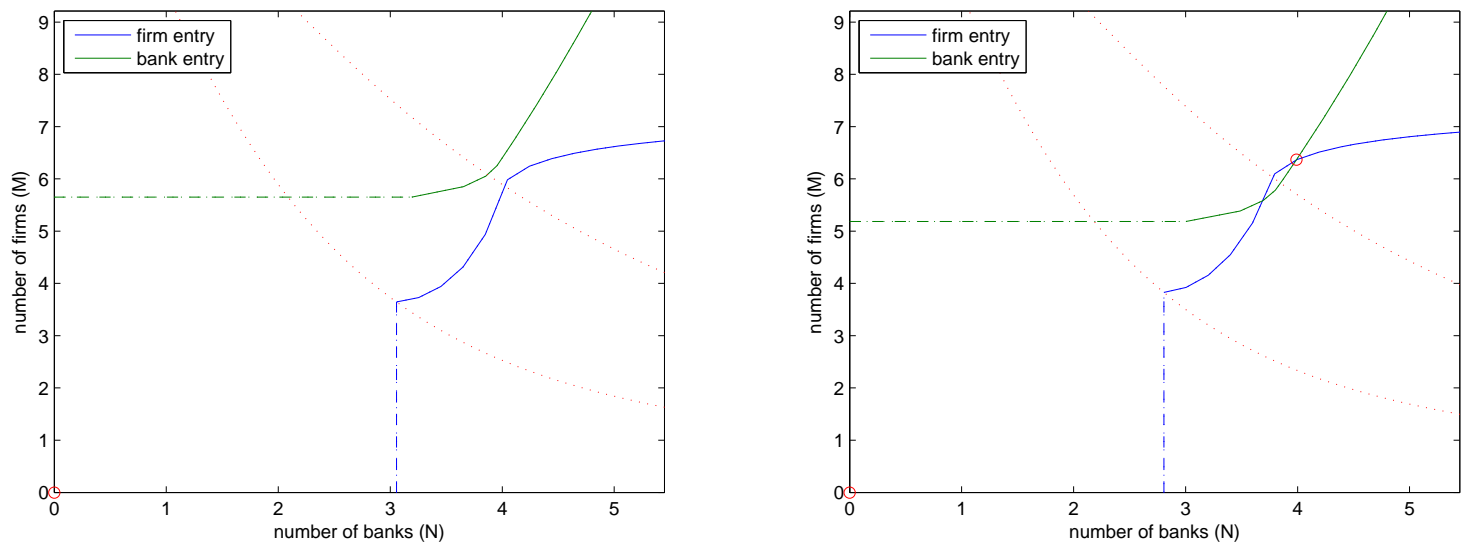

III.3. Policy implications. The last section highlights the role of the riskfree rate in decreasing the rents of entrepreneurs and bank managers and thus increasing the efficiency of the allocation of capital. This section analyzes the resilience of the economy to aggregate and idiosyncratic shocks. The main result is that if the riskfree rate is high, the buffers against systemic shocks are small, thus making economic and financial breakdowns more likely.

Interest rate policy and the efficiency/stability tradeoff. This section analyzes the effect of an income shock and a possible reaction by a policymaker. We then discuss the efficiency/stability tradeoff facing a policymaker. The left panel of Figure 9 shows the effect of a drop in capital $y$. By increasing the normalized cost $\delta_{e}$ and $\delta_{b}$, it makes the production equilibrium no longer viable. In this economy, the no-production equilibrium is the only equilibrium. There is a discontinuity in the sense that a bad shock can be strong enough to eliminate the production equilibrium which in the long-run, leads to the exit of all firms and banks. Facing large shocks, the policymaker can lower the riskfree interest rate (see right panel of Figure 9). Lowering the riskfree interest rate increases the relative attractiveness 
of risky investment, leading to more bank and firm profits and restoring the viability of the production equilibrium.

The policymaker therefore faces a efficiency/stability tradeoff in trying to maximize the representative investor welfare $U$. On the one hand, the risk of an economic collapse (switching to the no-production equilibrium if the production equilibrium disappears) generates an expected welfare loss. A low riskfree interest rate mitigates such a risk. On the other hand, the lack of competition increase the distortion in the allocation of capital and a low riskfree interest allows banks and firms to exercise more bargaining power. The goal of the policymaker is to balance the risk that bad shocks will dislocate the production economy with the costs of distorted capital allocation.

Remark on monetary policy in emerging economies: monetary authorities have a weaker instrument in open economies (especially in emerging economies) since lowering interest rates lead to capital outflows. In this case, other mechanisms are needed to stimulate the economy or prevent banking crises.

The impact of idiosyncratic shocks under short-term entry constraints. This section focuses on the aggregate effect of idiosyncratic bank failures under short-term bank entry constraints. As in the aggregate shock case, this lead to a discontinuity in the impact of the shock. Starting from the production equilibrium in Figure 10, assume that a certain number of banks fail for idiosyncratic reasons. Until these failed banks can be replaced, the cost of financial services increases which leads to the exit of firms. If the number of failed banks is small (first case) the economy moves to the free entry conditions for firms. At this point, banks make positive profits, the marginal incentives of bank managers are to enter, and the bank entry constraint is binding. When the banks start entering again, the economy can move back to the optimal production equilibrium.

If the number of failed banks is large (second case), the number of firms first reaches the point of free entry for banks. As this point, as the number of firms further decreases, banks 
FiguRE 10.

Dynamics after idiosyncratic shocks under short-term entry constraints. This figure represents the dynamics of the economy after the failure of banks under short-term bank entry constraints (ie. the number of banks $N$ can only decrease). In the first case, there is a small number of failures and the economy jumps to the set of firms and banks represented by the red cross (right of the red vertical line). Under bank entry constraints, following the stability discussion of Section III.1, the number of firms decreases and the system converges to the red diamond on the firm free entry curve. In the second case, there is large number of failures, and the economy jumps to the red plus sign (left of the vertical line). Under bank entry constraints, the number of firms decreases to the first triangle, and at this point, the economy collapses into the no-production equilibrium.

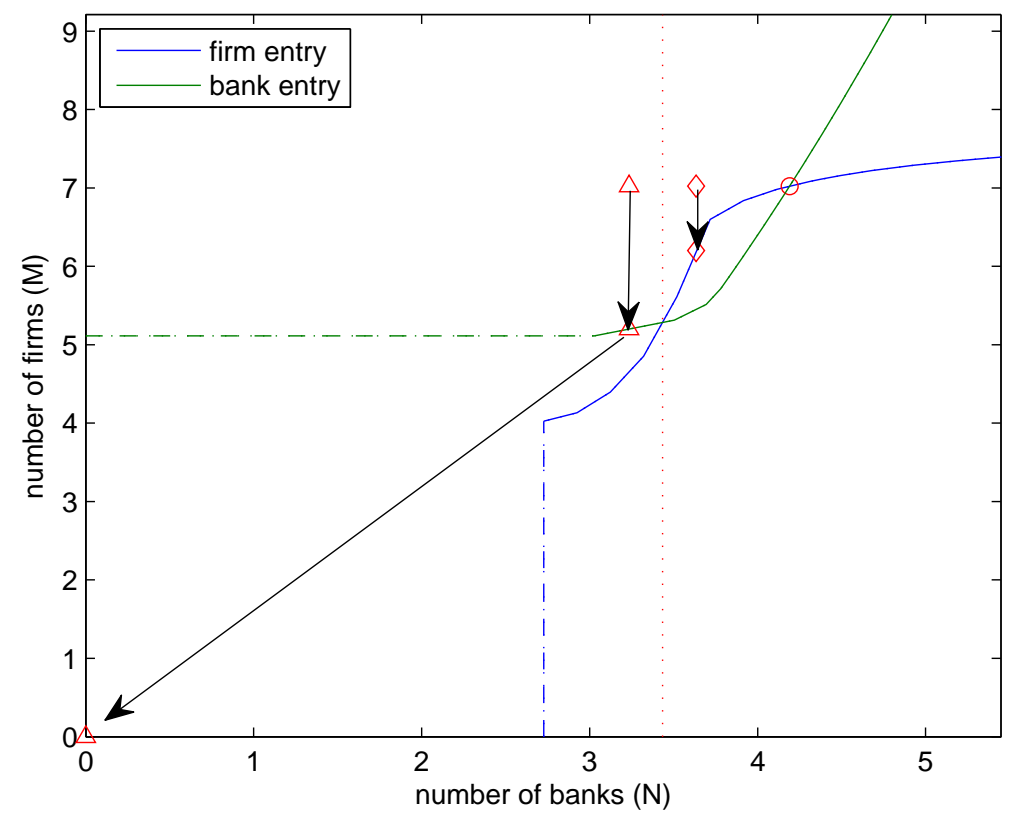

make negative profit and more banks fail. This reinforcing feedback loop lead to a financial and economic breakdown and the economy collapses into the no-production equilibrium. In this case, a loosening of monetary policy can move the vertical red line left and prevent the crash until the bank entry constraint is relaxed.

\section{A MODEL WITH BANK-FIRM CONGLOMERATES}

This section discusses vertical integration in bank-firm decisions and how this affects the resilience of the economy to shocks. In a model in which investment and financing is vertically integrated, the bank-firm conglomerates earn large rents which on the one side, further 
distorts the allocation of capital (and is partially compensated by more riskfree investment), but on the other side serve as a larger buffer against shocks. Historically, many countries have had a banking sector that would form long-term relationships with industrial firms. ${ }^{20}$ Vertical integration is modeled by introducing one monopolist firm per sector. Several sectors are pooled together within an industrial-financial conglomerate. The number of banks is pinned down in equilibrium so that the bank-firms conglomerate makes zero profit.

Similarly to Equation (2.1) in Section II.1, the supply of capital per firms/sector is

$$
K(\rho)=p y-\frac{\rho_{0} k_{0}}{\rho}
$$

In this case, the equilibrium return is such that $\frac{A-\rho}{\rho}=\frac{1}{\rho^{*}-1}$ or

$$
\rho=\sqrt{A \rho^{*}}
$$

The profit and investment are

$$
\begin{aligned}
\pi_{e} & =p A y\left[1-\frac{\rho^{*}}{\rho}\right]^{2}, \\
k & =p y\left[1-\frac{\rho^{*}}{\rho}\right]=p y\left[1-\sqrt{\frac{\rho^{*}}{A}}\right] .
\end{aligned}
$$

The aggregate budget constraint is

$$
k_{0}+p y\left[1-\sqrt{\frac{\rho^{*}}{A}}\right]=y \quad \Leftrightarrow \quad \frac{p \rho^{*}}{\rho_{0}}+p\left[1-\sqrt{\frac{\rho^{*}}{A}}\right]=1 .
$$

This implies

$$
\frac{\rho}{A}=\sqrt{\frac{\rho^{*}}{A}}=\frac{\rho_{0}}{2 A}+\sqrt{\left(\frac{\rho_{0}}{2 A}\right)^{2}+\frac{\rho_{0}}{A}\left(\frac{1-p}{p}\right)} .
$$

From there, the floor rate $\rho^{*}$ is always higher in the conglomerate case of this section than in the competition case of the previous sections. Similarly, the risky rates are lower in

\footnotetext{
${ }^{20}$ Crédit Mobilier in the 19th century in France, Hausbank system in Germany and conglomerates in Japan and Korea. Da Rin and Hellmann (2002) discuss the role of large banks to solve this coordination problem.
} 
the conglomerate case than in the competitive case. Since the welfare of the representative investor is $U\left(\rho^{*}, z, M\right)=\log (p y)+(1-p) \log \left(\rho^{*}\right)+\frac{p}{z} \int_{0}^{z} \log (\rho)$, there is a welfare loss due to the exercise of the monopoly power by the conglomerate (compared to the competitive case). The zero-profit condition pinning down the number of banks is

$$
\begin{aligned}
& 2 z p A y\left[1-\frac{\rho^{*}}{\rho}\right]^{2}=2 f_{e} z+f_{b}+2 f_{\varphi} \int_{0}^{z} \varphi d \varphi \\
\Leftrightarrow & {\left[1-\frac{\rho_{0}}{2 A}+\sqrt{\left(\frac{\rho_{0}}{2 A}\right)^{2}+\frac{\rho_{0}}{A}\left(\frac{1-p}{p}\right)}\right]^{2}=\kappa_{e}^{2}+\frac{\kappa_{b}}{z}+\frac{\kappa_{\varphi} z}{2} . }
\end{aligned}
$$

Proposition 2. Bank-firm conglomerates distort more the allocation of capital than competitive firms and banks but by earning larger rents, they also make the economy more resilient to shocks.

Although pricing distortions are larger in the conglomerate case, it improves on coordination issues. So when there are large problems with coordination failures, for instance in early stages of industrialization, a structure of the banking sector organized around noncompetitive banks might help development. In later development stages, when coordination is easier, a competitive banking sector is more preferable.

\section{Conclusion}

This paper presents of model in which the action of monetary authorities is motivated by the efficiency of the allocation of capital as well as the stability of the financial system. Fragility is not caused here by bank runs and the inability of depositors to coordinate. An efficiency/stability tradeoff emerges from the complementarities that link the investment decisions of firms and the financial markup decisions of banks. Bank competition determines the return received by a representative investor on his risky investments. Because of the complementarity between bank and firm decisions, multiple equilibria may exist, including a no-production "collapse." For a sufficiently large negative shock (low capital and/or 
low expected productivity), a collapse becomes the unique equilibrium. These results have implications for policy responses to financial crises. Policy authorities can potentially prevent financial damage through interventions designed to increase the profitability of firms and banks. However the downside of such interventions is to decrease competition in the economy (between firms and between banks) and to distort the allocation of capital, which creates a welfare loss for the representative investor. This efficiency/stability tradeoff creates a motive for low interest-rate policies during financial crises and high interest-rate policies during economic booms.

\section{A: Appendix}

A1: Lemma 1. With $\rho^{*}=\frac{\rho_{0} k_{0}}{p y}$, introduce $\tilde{\rho}^{*}=\rho^{*} / A \leq 1$ and $\Phi=\kappa_{\varphi}(2 z-\varphi)$.

- First, we look at the maximum $\xi_{m}$ of $\xi\left[\frac{1}{\sqrt{\tilde{\rho}^{*} M(1+\xi)+\left(\frac{M-1}{2}\right)^{2}}-\frac{M-1}{2}}-1\right]$. Introduce $s=\sqrt{\tilde{\rho}^{*} M(1+\xi)+\left(\frac{M-1}{2}\right)^{2}}-$ $\frac{M-1}{2}$. This is equivalent to finding the maximum $s_{m}$ of $\left[\frac{s(s+(M-1))}{\tilde{\rho}^{*} M}-1\right]\left[\frac{1}{s}-1\right]$. The first-order condition is $2 s^{3}-(2-M) s^{2}-\tilde{\rho}^{*} M=0$. We introduce ${ }^{21}$

$$
q=-\frac{(M-2)^{2}}{6^{2}} ; \quad r=\frac{54 \tilde{\rho}^{*} M+(2-M)^{3}}{6^{3}}
$$

The discriminant is

$$
\Delta=q^{3}+r^{2}=\frac{\left((2-M)^{3}+54 \tilde{\rho}^{*} M\right)^{2}-(2-M)^{6}}{6^{6}}=\frac{\tilde{\rho}^{*} M\left((2-M)^{3}+27 \tilde{\rho}^{*} M\right)}{432}
$$

When the discriminant is positive, there is a unique real root

$$
s_{m}=\sqrt[3]{r+\sqrt{\kappa_{e}}}+\sqrt[3]{r-\sqrt{\kappa_{e}}}-\frac{2-M}{6}
$$

The maximum $z_{m}$ as a function of $\rho^{*}$ is decreasing and for $\rho^{*}=0, s=0$ and $z_{m}\left(\rho^{*}=0\right)=\frac{M-1}{M}<1$.

This implies for any $\rho^{*}$, we have

$$
z_{m} \leq \frac{M-1}{M}<1
$$

- Second, we solve $\tilde{\rho}^{*} \xi\left[\frac{1}{\sqrt{\tilde{\rho}^{*} M(1+\xi)+\left(\frac{M-1}{2}\right)^{2}}-\frac{M-1}{2}}-1\right]=\Phi$. This is equivalent to

$$
\tilde{\rho}^{*}\left[\frac{s(s+(M-1))}{\tilde{\rho}^{*} M}-1\right]\left[\frac{1}{s}-1\right]=\Phi
$$

\footnotetext{
${ }^{21}$ For $a x^{3}+b x^{2}+c x+d$, let $q=\frac{3 a c-b^{2}}{9 a^{2}}$ and $r=\frac{9 a b c-27 a^{2} d-2 b^{3}}{54 a^{3}}$. The discriminant is $\Delta=q^{3}+r^{2}$.
} 
Intuitively, if $\Phi \in\left[0, f_{\varphi} z_{m}\right]$, this equation has two positive roots and we are looking for the smaller one. This yields

$$
s^{3}+(M-2) s^{2}-\left[\left(\tilde{\rho}^{*}-\Phi+1\right) M-1\right] s+\tilde{\rho}^{*} M=0
$$

We introduce

$$
\begin{aligned}
q & =-\frac{(2-M)^{2}+3\left[\left(\tilde{\rho}^{*}-\Phi+1\right) M-1\right]}{3^{2}} \\
r & =\frac{(2-M)^{3}+\frac{9(2-M)\left[\left(\tilde{\rho}^{*}-\Phi+1\right) M-1\right]-27 \tilde{\rho}^{*} M}{2}}{3^{3}}
\end{aligned}
$$

The discriminant $\Delta=q^{3}+r^{2}$ is then

$$
\begin{aligned}
\Delta= & \frac{M}{4 * 3^{3}}\left[4\left(\tilde{\rho}^{*}\right)^{3} M^{2}+\left(\tilde{\rho}^{*}\right)^{2} M\left(M^{2}-2 M(5+6 \Phi)+1\right)-2 \tilde{\rho}^{*}\left[M^{2}(1+\Phi)-M\left(4+\Phi+6 \Phi^{2}\right)+10 \Phi+1\right]\right. \\
& \left.\ldots+M^{3}(1+\Phi)^{2}-2 M^{2}\left(2 \Phi^{3}+4 \Phi^{2}+\Phi+1\right)+M\left(1+8 \Phi-8 \Phi^{2}\right)-4 \Phi\right]
\end{aligned}
$$

A2: Corollary 2. A sufficient condition for this result is $M>2$, condition that we assume.

- First, we differentiate expr $=\tilde{\rho}^{*}\left[\frac{1}{\sqrt{\tilde{\rho}^{*} M(1+\xi)+\left(\frac{M-1}{2}\right)^{2}}-\frac{M-1}{2}}-1\right]$ with respect to $\tilde{\rho}^{*}$

$$
\begin{aligned}
\frac{\partial \operatorname{expr}}{\partial \tilde{\rho}^{*}} & =\frac{1}{\sqrt{\tilde{\rho}^{*} M(1+\xi)+\left(\frac{M-1}{2}\right)^{2}}-\frac{M-1}{2}}-1-\frac{\tilde{\rho}^{*} M(1+\xi)}{2 \sqrt{\tilde{\rho}^{*} M(1+\xi)+\left(\frac{M-1}{2}\right)^{2}}}\left(\frac{1}{\sqrt{\tilde{\rho}^{*} M(1+\xi)+\left(\frac{M-1}{2}\right)^{2}}-\frac{M-1}{2}}\right)^{2} \\
& =\frac{1}{2 \sqrt{\tilde{\rho}^{*} M(1+\xi)+\left(\frac{M-1}{2}\right)^{2}}}-1 \leq 0
\end{aligned}
$$

The last inequality depending on $1-4 \tilde{\rho}^{*} M(1+\xi)-(M-1)^{2}$ which is negative whenever $M \leq 2$.

- Second we differentiate $s=\sqrt{\tilde{\rho}^{*} M(1+\xi)+\left(\frac{M-1}{2}\right)^{2}}-\frac{M-1}{2}$ with respect to $M$

$$
\begin{aligned}
\frac{\partial s}{\partial M} & =\frac{1}{2}\left[\frac{\tilde{\rho}^{*}(1+\xi)+\frac{M-1}{2}}{\sqrt{\tilde{\rho}^{*} M(1+\xi)+\left(\frac{M-1}{2}\right)^{2}}}-1\right] \\
& =-\frac{1}{2}\left[\frac{\tilde{\rho}^{*}(1+\xi)\left[1-\tilde{\rho}^{*}(1+\xi)\right]}{\sqrt{\tilde{\rho}^{*} M(1+\xi)+\left(\frac{M-1}{2}\right)^{2}}}\right]<0
\end{aligned}
$$

since $\tilde{\rho}^{*}(1+\xi)<1$.

Since $\tilde{\rho}^{*} \xi\left[\frac{1}{\sqrt{\tilde{\rho}^{*} M(1+\xi)+\left(\frac{M-1}{2}\right)^{2}}-\frac{M-1}{2}}-1\right]$ is increasing in $\xi$ on $\left[0, \hat{\xi}\left(\tilde{\rho}^{*}, M\right)\right]$, these conditions imply that $\xi\left(\varphi \mid \tilde{\rho}^{*}, z, M\right)$ is increasing in $\tilde{\rho}^{*}$ and decreasing in $M$. 


\section{A4: Lemma 2.}

- The expression $\left(1-\sqrt{\tilde{\rho}^{*} M(1+\xi)+\left(\frac{M-1}{2}\right)^{2}}+\frac{M-1}{2}\right)$ is increasing in $\xi$ and $\tilde{\rho}^{*}$ and decreasing in $M$, and $\xi\left(\varphi \mid \tilde{\rho}^{*}, z, M\right)$ is increasing in $\tilde{\rho}^{*}$ and $z$ and decreasing in $M$ so that

$$
I_{i}\left(\tilde{\rho}^{*}, z, M\right)=\sqrt[i]{\frac{1}{z} \int_{0}^{z}\left(1-\sqrt{\tilde{\rho}^{*} M\left(1+\xi\left(\varphi \mid \tilde{\rho}^{*}, z, M\right)\right)+\left(\frac{M-1}{2}\right)^{2}}+\frac{M-1}{2}\right)^{i} d \varphi}
$$

is decreasing in $\tilde{\rho}^{*}$ and $z$ and increasing in $M$. The expression

$$
\frac{1-\sqrt{\tilde{\rho}^{*} M(1+\xi)+\left(\frac{M-1}{2}\right)^{2}}+\frac{M-1}{2}}{M}=\frac{1-\tilde{\rho}^{*}(1+\xi)}{\frac{M+1}{2}+\sqrt{\tilde{\rho}^{*} M(1+\xi)+\left(\frac{M-1}{2}\right)^{2}}}
$$

is decreasing in $M$.

- Technical properties of $I_{i}\left(\tilde{\rho}^{*}, z, M\right)$. The economy under $\tilde{\rho}^{*}=1$ and $\tilde{\rho}^{*}=0$.

- If $\tilde{\rho}^{*}=1$, then $\xi=0, r_{l}=0$ and the profit of firms is zero. We have $I_{i}(1, z, M)=0$.

- If $\tilde{\rho}^{*}=0$, then $r_{l} \simeq \frac{p A y}{M}\left(\frac{M-1}{(1+\xi) M}\right), \xi_{m}=+\infty$ and if $\Phi<\frac{M-1}{M}$, then $\xi=\frac{\Phi}{(M-1) / M-\Phi}$. Then

$$
I_{i}(0, z, M)=1 .
$$

We have $I_{i}\left(\tilde{\rho}^{*}, z, M\right)$ decreasing in $z$ from $I_{i}\left(\tilde{\rho}^{*}, 0, M\right)=1+\frac{M-1}{2}-\sqrt{\tilde{\rho}^{*} M+\left(\frac{M-1}{2}\right)^{2}}$ to $I_{i}\left(\tilde{\rho}^{*}, z_{m}, M\right)=$ $1+\frac{M-1}{2}-\sqrt{\tilde{\rho}^{*} M\left(1+\xi_{m}\right)+\left(\frac{M-1}{2}\right)^{2}}$. Also $I_{i}(0, z, M)=1$.

- Solving $I_{i}\left(\tilde{\rho}^{*}, z, M\right)$ is closed form. Introduce $\tilde{\rho}^{*}=\frac{r_{0}}{p A y} \leq 1$ and $\Phi=\kappa_{\varphi}(2 z-\varphi)$. We have $\tilde{\rho}^{*} \xi\left[\frac{1}{\sqrt{\tilde{\rho}^{*} M(1+\xi)+\left(\frac{M-1}{2}\right)^{2}}-\frac{M-1}{2}}-1\right]=\Phi$. Introduce $s=\sqrt{\tilde{\rho}^{*} M(1+\xi)+\left(\frac{M-1}{2}\right)^{2}}-\frac{M-1}{2}$. Then

$$
\begin{aligned}
\Phi=F^{\prime \prime}(s) & =\tilde{\rho}^{*}\left[\frac{s(s+(M-1))}{\tilde{\rho}^{*} M}-1\right]\left[\frac{1}{s}-1\right] \\
& =\frac{1}{M}\left(-s^{2}-(M-2) s+\left[\left(\tilde{\rho}^{*}+1\right) M-1\right]-\frac{\tilde{\rho}^{*} M}{s}\right)
\end{aligned}
$$

We have

$$
\begin{aligned}
F^{\prime}(s) & =\frac{1}{M}\left(-\frac{s^{3}}{3}-\frac{(M-2) s^{2}}{2}+\left[\left(\tilde{\rho}^{*}+1\right) M-1\right] s-\tilde{\rho}^{*} M \log (s)\right) \\
F(s) & =\frac{1}{M}\left(-\frac{s^{4}}{12}-\frac{(M-2) s^{3}}{6}+\left[\left(\tilde{\rho}^{*}+1\right) M-1\right] \frac{s^{2}}{2}-\tilde{\rho}^{*} M s(\log (s)-1)\right)
\end{aligned}
$$


Let $G$ the inverse of $F^{\prime \prime}: G=\left(F^{\prime \prime}\right)^{-1}$ ie $s=G(\Phi)=\sqrt{\tilde{\rho}^{*} M(1+\xi(\Phi))+\left(\frac{M-1}{2}\right)^{2}}-\frac{M-1}{2}$.

$$
\begin{aligned}
I_{1} & =\int_{a}^{b}\left[1-\sqrt{\tilde{\rho}^{*} M(1+\xi(\varphi))+\left(\frac{M-1}{2}\right)^{2}}+\frac{M-1}{2}\right] d \varphi \\
& =\frac{1}{\kappa_{\varphi}} \int_{\kappa_{\varphi}(2 z-b)}^{\kappa_{\varphi}(2 z-a)}\left[1-\sqrt{\tilde{\rho}^{*} M(1+\xi(\Phi))+\left(\frac{M-1}{2}\right)^{2}}+\frac{M-1}{2}\right] d \Phi \\
& =\frac{1}{\kappa_{\varphi}} \int_{G\left(\kappa_{\varphi}(2 z-b)\right)}^{G\left(\kappa_{\varphi}(2 z-a)\right)}(1-s) F^{\prime \prime \prime}(s) d s=\frac{1}{\kappa_{\varphi}}\left[(1-s) F^{\prime \prime}(s)+F^{\prime}\right]_{G\left(\kappa_{\varphi}(2 z-a)\right)}^{G(2 z-b))} \\
& =\frac{1}{\kappa_{\varphi} M}\left[\frac{2 s^{3}}{3}+\frac{(M-4) s^{2}}{2}-(M-2) s+M-1+\tilde{\rho}^{*} M\left(2-\frac{1}{s}-\log (s)\right)\right]_{G\left(\kappa_{\varphi}(2 z-b)\right)}^{G\left(\kappa_{\varphi}(2 z-a)\right)} \\
& =\frac{1}{\kappa_{\varphi} M}\left[\frac{2 s^{3}}{3}+\frac{(M-4) s^{2}}{2}-(M-2) s-\tilde{\rho}^{*} M\left(\frac{1}{s}+\log (s)\right)\right]_{G(2 z-b)}^{G(2 z-a)}
\end{aligned}
$$

$$
\begin{aligned}
I_{2}^{2} & =\int_{a}^{b}\left[1-\sqrt{\tilde{\rho}^{*} M(1+\xi(\varphi))+\left(\frac{M-1}{2}\right)^{2}}+\frac{M-1}{2}\right]^{2} d \varphi \\
& =\frac{1}{\kappa_{\varphi}} \int_{\kappa_{\varphi}(2 z-b)}^{\kappa_{\varphi}(2 z-b)}\left[1-\sqrt{\tilde{\rho}^{*} M(1+\xi(\Phi))+\left(\frac{M-1}{2}\right)^{2}}+\frac{M-1}{2}\right]^{2} d \Phi \\
& =\frac{1}{\kappa_{\varphi}} \int_{G\left(\kappa_{\varphi}(2 z-b)\right)}^{G\left(\kappa_{\varphi}(2 z-a)\right)}(1-s)^{2} F^{\prime \prime \prime}(s) d s=\frac{1}{\kappa_{\varphi}}\left[(1-s)^{2} F^{\prime \prime}+2(1-s) F^{\prime}+2 F\right]_{G\left(\kappa_{\varphi}(2 z-b)\right)}^{G\left(\kappa_{\varphi}(2 z-a)\right)} \\
& =\frac{1}{\kappa_{\varphi} M}\left[-\frac{s^{4}}{2}-\frac{(M-6) s^{3}}{3}+(M-3) s^{2}+M-1-(M-2) s+\tilde{\rho}^{*} M\left(s+3-\frac{1}{s}-2 \log (s)\right)\right]_{G\left(\kappa_{\varphi}(2 z-b)\right)}^{G\left(\kappa_{\varphi}(2 z-a)\right)} \\
& =\frac{1}{\kappa_{\varphi} M}\left[-\frac{s^{4}}{2}-\frac{(M-6) s^{3}}{3}+(M-3) s^{2}-(M-2) s+\tilde{\rho}^{*} M\left(s-\frac{1}{s}-2 \log (s)\right)\right]_{G\left(\kappa_{\varphi}(2 z-b)\right)}^{G\left(\kappa_{\varphi}(2 z-a)\right)}
\end{aligned}
$$

V.1. Lemma 3. Technical remarks:

- when the distance between banks $z$ is close to 0 , the markup $\xi$ is also close to zero and $I_{1}\left(\rho^{*}, 0, M\right)=$ $1-\frac{\frac{\rho^{*} M}{A}}{\sqrt{\frac{\rho^{*} M}{A}+\left(\frac{M-1}{2}\right)^{2}+\frac{M-1}{2}}}$. The equation

$$
1=\frac{p \rho^{*}}{\rho_{0}}+p\left[1-\frac{\frac{\rho^{*} M}{A}}{\sqrt{\frac{\rho^{*} M}{A}+\left(\frac{M-1}{2}\right)^{2}}+\frac{M-1}{2}}\right]
$$

pins down $\rho_{\min }^{*}(M)$. 
- when the distance between banks $z$ is large (higher than $z_{m}\left(\rho^{*}, M\right)$ ), the markup is $\hat{\xi}_{m}\left(\rho^{*}, M\right)$ and the equation

$$
1=\frac{p \rho^{*}}{\rho_{0}}+p\left[1-\frac{\frac{\rho^{*}\left(1+\hat{\xi}\left(\rho^{*}, M\right)\right) M}{A}}{\sqrt{\frac{\rho^{*}\left(1+\hat{\xi}\left(\rho^{*}, M\right)\right) M}{A}+\left(\frac{M-1}{2}\right)^{2}}+\frac{M-1}{2}}\right]
$$

pins down $\rho_{\max }^{*}(M)$. The threshold for $\rho^{*}=\rho_{\max }^{*}(M)$ is $z=z_{m}\left(\rho_{\max }^{*}(M), M\right)$.

V.2. Lemma 4. Inverting (2.9), we find $z=Z_{b}\left[z_{m}\left(\rho^{*}(z, M), M\right), M\right]$ with

$$
Z_{b}\left(z_{m}, M\right)= \begin{cases}\text { not defined (no entry) } & \text { if } z_{m}<\sqrt{\frac{2 \kappa_{b}}{\kappa_{\varphi} M}} \\ \left(z_{m}-\sqrt{\left.\frac{z_{m}^{2}}{2}-\frac{\kappa_{b}}{\kappa_{\varphi} M}\right)}\right. & \text { if } z_{m} \in\left[\sqrt{\frac{2 \kappa_{b}}{\kappa_{\varphi} M}}, \sqrt{\frac{4 \kappa_{b}}{\kappa_{\varphi} M}}\right] . \\ \sqrt{\frac{\kappa_{b}}{\kappa_{\varphi} M}} & \text { if } z_{m} \geq \sqrt{\frac{4 \kappa_{b}}{\kappa_{\varphi} M}}\end{cases}
$$

The minimum number of firms $M_{\min }^{b}$ is defined such that even if there is no competition for banks (ie. $\left.z=z_{m}\left(\rho^{*}, M\right)\right)$, the supply of capital from the representative agent and the number of firms are just enough to pay for the fixed cost for banking entry. More precisely, it is defined jointly with $\rho^{*}$ to be the solution of the system

$$
\begin{aligned}
1-\frac{p \rho^{*}}{\rho_{0}} & =p I_{1}\left(\rho^{*}, z_{m}\left(\rho^{*}, M\right), M\right), \\
\frac{\kappa_{b}}{\kappa_{\varphi}} & =\frac{M z_{m}\left(\rho^{*}, M\right)^{2}}{2} .
\end{aligned}
$$

V.3. Lemma 5. The minimum number of banks $N_{\min }^{e}$ (or equivalently the maximum distance between banks $\left.2 z_{\max }^{e}\right)$ is determined such that there is enough competition between banks to sustain firm entry. It is possible to show that $z=z_{m}\left(\rho^{*}, M\right)$ at $z_{\max }^{e}$. The system yielding the solution is

$$
\begin{aligned}
1-\frac{p \rho^{*}}{\rho_{0}} & =I_{1}\left(\rho^{*}, z_{m}\left(\rho^{*}, M\right), M\right), \\
\kappa_{e} M & =I_{2}\left(\rho^{*}, z_{m}\left(\rho^{*}, M\right), M\right), \\
z & =z_{m}\left(\rho^{*}, M\right) .
\end{aligned}
$$

\section{V.4. Lemma 6.}

- The budget constraint $1=\frac{p}{\rho_{0}} \rho^{*}+p-\frac{p}{z} \int_{0}^{z} s$ pins down implicity $\rho^{*}(z, M)$. In turn, define $\hat{s}(\xi \mid M)=$ $s\left(\xi \mid \rho^{*}(z, M), M\right)$, an increasing function of $\xi$ and decreasing in $M$. We study

$$
U(M)=\log \left(1-p+\frac{p}{z} \int_{0}^{z} \hat{s}(\xi \mid M) d \varphi\right)-\frac{p}{z} \int_{0}^{z} \log [s(\xi \mid M)] d \varphi
$$


The first-order condition is

$$
\frac{\frac{1}{z} \int_{0}^{z} \frac{\partial \hat{s}}{\partial M}}{1-p+\frac{p}{z} \int_{0}^{z} \hat{s}}-\frac{1}{z} \int_{0}^{z} \frac{1}{\hat{s}} \frac{\partial \hat{s}}{\partial M}
$$

Rearranging the terms, since $\frac{\partial \hat{s}}{\partial M}<0$, we have

$$
-\frac{1}{z} \int_{0}^{z} \frac{(1-p)\left(1-\frac{1}{z} \int_{0}^{z} \hat{s}\right)}{\hat{s}} \frac{\partial \hat{s}}{\partial M}>0
$$

The similar result that the utility is increasing in the number of banks $N$ is immediate.

- We study

$$
\bar{\rho}(M)=\frac{(1-p)^{2}}{\frac{p}{z} \int_{0}^{z}\left(\frac{1}{\rho_{0}}-\frac{1}{\hat{\rho}}\right)}+\frac{p}{z} \int_{0}^{z} \hat{\rho}
$$

The first-order condition is

$$
\frac{1}{z} \int_{0}^{z} \frac{\partial \hat{\rho}}{\partial M}\left[1-\left(\frac{1-p}{p} \frac{\frac{1}{\hat{\rho}}}{\frac{1}{z} \int_{0}^{z}\left(\frac{1}{\rho_{0}}-\frac{1}{\hat{\rho}}\right)}\right)^{2}\right]
$$

which is positive since $p \rho>\rho_{0}$.

- Solving in closed form welfare and expected return. Introduce $\tilde{\rho}^{*}=\rho^{*} / A$. We have

$$
\left.\frac{F^{\prime \prime}(s)}{s}=\frac{1}{M}\left(-s-(M-2)+\frac{\left[\left(\tilde{\rho}^{*}+1\right) M-1\right]}{s}-\frac{\tilde{\rho}^{*} M}{s^{2}}\right)\right)
$$

so that

$$
\left.\int \frac{F^{\prime \prime}(s)}{s} d s=\frac{1}{M}\left(-\frac{s^{2}}{2}-(M-2) s+\left[\left(\tilde{\rho}^{*}+1\right) M-1\right] \log (s)+\frac{\tilde{\rho}^{*} M}{s}\right)\right)
$$

$$
\begin{aligned}
\int_{a}^{b} \log \left(\frac{\rho}{\tilde{\rho}^{*}}\right) d \varphi & =-\int_{a}^{b} \log \left(\sqrt{\tilde{\rho}^{*} M(1+\xi(\varphi))+\left(\frac{M-1}{2}\right)^{2}}-\frac{M-1}{2}\right) d \varphi \\
& =-\frac{1}{\kappa_{\varphi}} \int_{\kappa_{\varphi}(2 z-a)}^{\kappa_{\varphi}(2 z-b)} \log \left(\sqrt{\tilde{\rho}^{*} M(1+\xi(\Phi))+\left(\frac{M-1}{2}\right)^{2}}-\frac{M-1}{2}\right) d \Phi \\
& =-\frac{1}{\kappa_{\varphi}} \int_{G\left(\kappa_{\varphi}(2 z-a)\right)}^{G\left(\kappa_{\varphi}(2 z-b)\right)} \log (s) F^{\prime \prime \prime}(s) d s \\
& =-\frac{1}{\kappa_{\varphi}}\left[\log (s) F^{\prime \prime}\right]_{G\left(\kappa_{\varphi}(2 z-a)\right)}^{G\left(\kappa_{\varphi}(2 z-b)\right.} \frac{1}{\kappa_{\varphi}} \int_{G\left(\kappa_{\varphi}(2 z-a)\right)}^{G\left(\kappa_{\varphi}(2 z-b)\right)} \frac{F^{\prime \prime}(s)}{s} d s \\
& =-\frac{1}{\kappa_{\varphi} M}\left[\log (s)\left(-s^{2}-(M-2) s-\frac{\tilde{\rho}^{*} M}{s}\right)+\left(-\frac{s^{2}}{2}-(M-2) s+\frac{\tilde{\rho}^{*} M}{s}\right)\right]_{G\left(\kappa_{\varphi}(2 z-b)\right)}^{G\left(\kappa_{\varphi}(2 z-a)\right)}
\end{aligned}
$$




$$
\begin{aligned}
& \left.\frac{F^{\prime \prime}(s)}{s^{2}}=\frac{1}{M}\left(-1-\frac{M-2}{s}+\frac{\left[\left(\tilde{\rho}^{*}+1\right) M-1\right]}{s^{2}}-\frac{\tilde{\rho}^{*} M}{s^{3}}\right)\right) \\
& \left.\int \frac{F^{\prime \prime}(s)}{s^{2}} d s=\frac{1}{M}\left(-s-(M-2) \log (s)-\frac{\left(\tilde{\rho}^{*}+1\right) M-1}{s}+\frac{2 \tilde{\rho}^{*} M}{s^{2}}\right)\right) \\
& \int_{a}^{b}\left(\frac{\tilde{\rho}^{*}}{\rho}-1\right) d \varphi=\int_{a}^{b}\left(\frac{1}{\sqrt{\tilde{\rho}^{*} M(1+\xi(\varphi))+\left(\frac{M-1}{2}\right)^{2}}-\frac{M-1}{2}}-1\right) d \varphi \\
& =\frac{1}{\kappa_{\varphi}} \int_{\kappa_{\varphi}(2 z-a)}^{\kappa_{\varphi}(2 z-b)}\left(\frac{1}{\sqrt{\tilde{\rho}^{*} M(1+\xi(\Phi))+\left(\frac{M-1}{2}\right)^{2}}-\frac{M-1}{2}}-1\right) d \Phi \\
& =\frac{1}{\kappa_{\varphi}} \int_{G\left(\kappa_{\varphi}(2 z-a)\right)}^{G\left(\kappa_{\varphi}(2 z-b)\right)}\left(\frac{1-s}{s}\right) F^{\prime \prime \prime}(s) d s \\
& =\frac{1}{\kappa_{\varphi}}\left[\left(\frac{1-s}{s}\right) F^{\prime \prime}(s)\right]_{G\left(\kappa_{\varphi}(2 z-a)\right)}^{G\left(\kappa_{\varphi}(2 z-b)\right)}+\frac{1}{\kappa_{\varphi}} \int_{G\left(\kappa_{\varphi}(2 z-a)\right)}^{G\left(\kappa_{\varphi}(2 z-b)\right)} \frac{F^{\prime \prime}(s)}{s^{2}} d s \\
& =\frac{1}{\kappa_{\varphi}}\left[-s-\frac{\tilde{\rho}^{*} M}{s^{2}}+s^{2}+(M-2) s+\frac{\tilde{\rho}^{*} M}{s}-s-(M-2) \log (s)+\frac{2 \tilde{\rho}^{*} M}{s^{2}}\right]_{G\left(\kappa_{\varphi}(2 z-a)\right)}^{G\left(\kappa_{\varphi}(2 z-b)\right)} \\
& =\frac{1}{\kappa_{\varphi}}\left[s^{2}+(M-4) s-(M-2) \log (s)-\frac{\tilde{\rho}^{*} M}{s}+\frac{\tilde{\rho}^{*} M}{s^{2}}\right]_{G\left(\kappa_{\varphi}(2 z-a)\right)}^{G\left(\kappa_{\varphi}(2 z-b)\right)}
\end{aligned}
$$




\section{ReferenCes}

Acemoglu, D., And F. Zilibotti (1997): "Was Prometheus Unbound by Chance? Risk, Diversification, and Growth," Journal of Political Economy, 105, 709-751.

Adrian, T., AND H. Shin (2008, forthcoming): "Liquidity and Leverage," Journal of Financial Intermediation.

Allen, F., And D. Gale (2000): Comparing Financial Systems. Cambridge: MIT Press. Bank of England (2008): Financial Stability Report.

Beim, D., And C. Calomoris (2001): Emerging Financial Markets. McGraw-Hill: New York.

Berger, A., N. Miller, M. Petersen, R. Rajan, and J. Stein (2005): "Does Function follow Organizational Form? Evidence from the Lending Practices of Large and Small Banks," Journal of Financial Economics.

Bernanke, B., And M. Gertler (1989): "Agency Costs, Net Worth, and Business Fluctuations," American Economic Review.

_ (1990): "Financial Fragility and Economic Performance," Quarterly Journal of Economics.

Besanko, D., And A. Thakor (1992): "Banking Deregulation: Allocational Consequences of Relaxing Entry Barriers," Journal of Banking and Finance.

Bolton, P., and X. Freixas (2006): “Corporate Finance and the Monetary Transmission Mechanism," Review of Financial Studies, 19, 829-870.

Boyd, J., And G. De Nicolo (2005): "The Theory of Bank Risk Taking and Competition Revisited," Journal of Finance, 60, 1329-1343.

Brunnermeier, M., And L. Pedersen (2007): "Market Liquidity and Funding Liquidity,"

Caballero, R., and M. Hammour (1994): "The Cleansing Effect of Recession," American Economic Review, 84, 1350-1368. 
Caballero, R., T. Hoshi, and A. Kashyap (2008, forthcoming): "Zombie Lending and Depressed Restructuring in Japan," American Economic Review.

Carletti, E. (2005, forthcoming): "Competition and Regulation in Banking," in Handbook in Financial Intermediation, ed. by A. Boot, and A. Thakor.

Cetorelli, N., and P. Strahan (2006): "Finance as a Barrier to Entry: Bank Competition and Industry Structure in Local U.S. Markets," Journal of Finance.

Ciccone, A., and K. Matsuyama (1996): "Start-up Costs and Pecuniary Externalities as Barriers to Economic Development," Journal of Development Economics.

Clafessens, S., A. Demirguc-Kunt, and H. Huizinga (2003): "How Does Foreign Entry Affect Domestic Banking Markets?," Journal of Banking and Finance.

Claessens, S., and L. Laeven (2004): "What Drives Bank Competition? Some International Evidence," Journal of Money, Credit and Banking.

(2005): "Financial Dependence, Banking sector competition and economic growth," Journal of European Economic Association.

Da Rin, M., And T. Hellmann (2002): "Banks as Catalysts for Industrialization," Journal of Financial Intermediation.

De Bandt, O., and P. Hartmann (2002): "Systemic Risk in Banking: A Survery," in Financial Crises, Contagion and the Lender of Last Resort - A Reader, ed. by C. Goodhart, and G. Illing, pp. 249-298.

Degryse, H., and S. Ongena (2005): "Distance, Lending Relationships and Competition," Journal of Finance.

Diamond, D. (1984): "Financial Intermediation and Delegated Monitoring," Review of Economic Studies.

Diamond, D., And P. Dybvig (1983): "Bank Runs, Deposit Insurance and Liquidity," Journal of Political Economy, 91, 401-419. 
Dick, A. (2008): "Demand Estimation and Consumer Welfare in the Banking Industry," Journal of Banking and Finance, 32, 1661-1676.

Djankov, S., R. La Porta, F. Lopez-De-Silanes, and A. Shleifer (2002): "The Regulation of Entry," Quarterly Journal of Economics.

European Central Bank (2008): "Financial Stability Review," .

Greenwood, J., And B. Jovanovic (1990): "Financial Development, Growth and the Distribution of Income," Journal of Political Economy.

Holmstrom, B., And J. Tirole (1997): "Financial Intermediation, Loanable Funds and the Real Sector," Quarterly Journal of Economics.

International Monetary Fund (2008): "Global Financial Stability Report,” .

Jayaratne, J., And P. Strahan (1996): "The Finance-Growth nexus: Evidence from Bank Branch Dergulation," Quarterly Journal of Economics.

Klapper, L., L. Laeven, and R. Rajan (2006): "Entry Regulation as a Barrier to Entrepreneurship," Journal of Financial Economics.

Martin, P., And H. Rey (2004): "Financial Super-Markets: Size Matters for Asset Trade," Journal of International Economics, 64, 335-361.

Melitz, M., and G. Ottaviano (2008): "Market Size, Trade and Productivity," Review of Economic Studies, 75, 295-316.

Obstfeld, M. (1994): "Risk-Taking, Global Diversification and Growth," American Economic Review.

Petersen, M., And R. Rajan (1995): "The Effect of Credit Market Competition on Lending Relationship," Quarterly Journal of Economics.

RAJAN, R. (1992): “Insiders and Outsiders: the Choice between Informed and Arm's-length Debt," Journal of Finance, 47, 1367-1400.

Repullo, R. (2005): "Liquidity, Risk Taking, and the Lender of Last Resort," International Journal of Central Banking, 1, 47-80. 
Rochet, J.-C., And X. Vives (2004): "Coordination Failures and the Lender of Last Resort: Was Bagehot Right After All?," Journal of the European Economic Assocation, 2, 1116-1147.

Saint-PAul, G. (1992): "Technological Choice, Financial Markets and Economic Development," European Economic Review.

Sussman, O. (1993): "A Theory of Financial Development," in Finance and Development: Issues and Experience, ed. by A. Giovannini.

Vogel, J. (2008): "Spatial Competition with Heterogeneous Firms," Journal of Political Economy, 116, 423-466.

Williamson, S. (1986): "Costly Monitoring, Financial Intermediation and Equilibrium Credit Rationing," Journal of Monetary Economics.

Winton, A. (1997): "Competition Among Financial Intermediaries When Diversification Matters," Journal of Financial Intermediation.

Yannelle, M.-O. (1997): "Banking Competition and Market Efficiency," Review of Economic Studies. 